\title{
Growth and collapse of the distributed subglacial hydrologic system of Kennicott Glacier, Alaska, USA, and its effects on basal motion
}

\author{
Timothy C. BARTHOLOMAUS, ${ }^{1,2,3,4}$ Robert S. ANDERSON, ${ }^{3,4}$ \\ Suzanne P. ANDERSON ${ }^{3,5}$ \\ ${ }^{1}$ Geophysical Institute, University of Alaska Fairbanks, 903 Koyukuk Drive, Fairbanks, Alaska 99775-7320, USA \\ E-mail: tbartholomaus@gi.alaska.edu \\ ${ }^{2}$ Department of Geology and Geophysics, University of Alaska Fairbanks, 900 Yukon Drive, \\ Fairbanks, Alaska 99775-5780, USA \\ ${ }^{3}$ Institute of Arctic and Alpine Research, University of Colorado at Boulder, Boulder, Colorado 80309-0450, USA \\ ${ }^{4}$ Department of Geological Sciences, University of Colorado at Boulder, Boulder, Colorado 80309-0399, USA \\ ${ }^{5}$ Department of Geography, University of Colorado at Boulder, Boulder, Colorado 80309-0260, USA
}

\begin{abstract}
Nearly 100 days of hourly glacier motion, hydrology and hydrochemistry measurements on Kennicott Glacier, Alaska, USA, demonstrate the complicated relationship between water and motion at the glacier bed. Our observations capture the transient glacier response to seasonal and daily melt cycles, and to a jökulhlaup that prompts a sixfold increase in glacier speed. Sliding is promoted whenever the water inputs to the glacier exceed the capacity of the subglacial hydrologic system to transmit the water. Sensitivity of sliding to daily meltwater inputs varies strongly through the season, implying that the state of the hydrologic system governs the sensitivity of basal sliding. A numerical model constructed to explore these relationships reveals: the roles of the effective pressure; the exponent to which this is taken in the 'sliding law' $(0.1<\gamma<0.6)$; glacier macroporosity $(\phi<2 \%)$; and the 'cavity-generating capacity' of the glacier bed, which encapsulates the sizes and spacing of bed roughness elements. Temporal changes in the effective pressure associated with evolution of both water inputs and subglacial water transmission capacity can explain the varying strength of diurnal velocity fluctuations of Kennicott Glacier. Spatial patterns of glacier macroporosity and of basal roughness govern variation in sensitivity of sliding to water inputs.
\end{abstract}

\section{INTRODUCTION}

The temporal evolution of glacier surface speeds varies among glaciers and between years, but often shares several basic features (Willis, 1995). Summer velocities are greater than winter velocities (e.g. Hooke and others, 1989); the melt season is often punctuated by discrete events that tend to occur during the spring and fall (including the so-called 'spring event'; e.g. Raymond and others, 1995); and diurnal variations may come and go (Bartholomaus and others, 2008) if they are present at all. Each of these variations in motion reflects a dynamic response of glacier basal motion to transient glacier hydrology. In the cases in which glacier water pressures are measured in concert with surface motion, high basal water pressures are often, although not always, linked with above-average rates of basal motion. These empirical studies suggest a 'sliding law' that incorporates an inverse power-law relationship between basal motion and the effective pressure: the water pressure subtracted from the ice overburden pressure (Bindschadler, 1983; Cuffey and Paterson, 2010). Schoof (2005) has suggested a slightly more sophisticated relationship, but the effective pressure remains an important term.

Other studies have shown that the state of the subglacial hydrologic system plays a critical role in the relationship between water and basal motion (e.g. Mair and others, 2001). As the subglacial hydrologic system evolves between distributed storage in linked cavities or till sheets, and channelized storage in efficient, high-discharge conduits, the links between basal water and basal motion change.
Glacier hydrology and its connection to glacier basal motion is never steady, as both the inputs of water from the glacier surface and the capacity of the subglacial hydrologic system to transmit water vary strongly on several timescales. This is what makes the hydrology-sliding connection both complicated and interesting.

Although dye-tracing and hydrochemical studies have aided the characterization of the subglacial hydrologic system in several instances (Nienow and others, 1998; Hock and others, 1999; Anderson and others, 2003a,b), the laborintensive work of this method and the size of ice sheets and many glaciers limits the utility of these methods. Boreholes offer direct observations, but without extraordinary effort (e.g. Harper and others, 2007) are generally limited to a few discrete points. At present, the technology to monitor directly the temporal and spatial evolution of the subglacial hydrologic system requires massive field campaigns; this inability to monitor the glacier bed presents a persistent challenge to those trying to explain and predict basal motion.

In a previous study stemming from the fieldwork discussed here (Bartholomaus and others, 2008), we reported that diurnal surface velocity variations were present during some periods of the Kennicott Glacier (Alaska, USA) GPS records, but were absent during others. We also found that when the daily-averaged water volume stored within the glacier was increasing, the rate of basal motion was well correlated with the rate of change of water storage on hourly timescales. In explanation of these observations, we suggested that high rates of basal motion resulted from the 


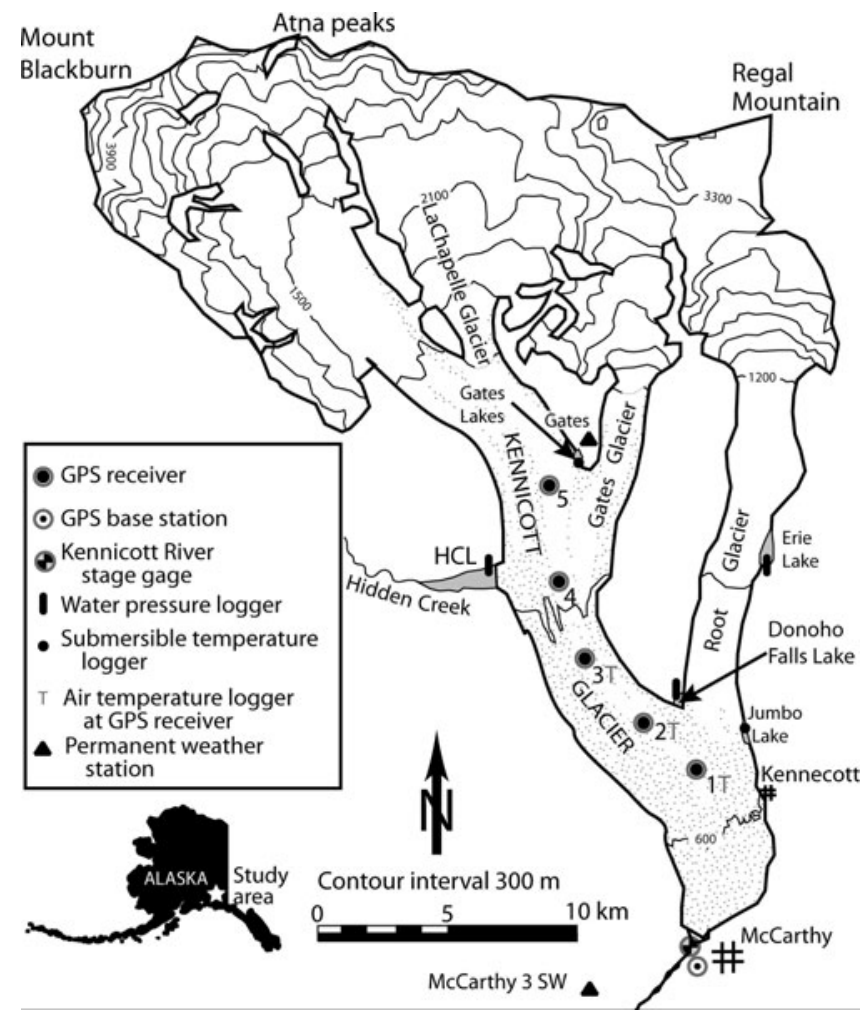

Fig. 1. Map of Kennicott Glacier, showing instrumentation installed in 2006. McCarthy and Kennecott are nearby town sites. Stippling indicates portion of glacier covered by rock debris.

backflow of water from efficient, channelized subglacial conduits into a distributed basal water system. We proposed that this shift in water storage was associated with increases in basal water storage as well as high basal water pressure.

Here we test this conceptual model by constructing a numerical model that explicitly acknowledges the transience inherent in glacier hydrology. We begin with a description of the field methods and data, focusing on the velocity and hydrologic data we seek to reproduce with our model. We then introduce the model and test it with synthetic data before running it with the water balance calculated for the 2006 Kennicott Glacier melt season (Bartholomaus and others, 2008). We conclude with a discussion of how the state of the glacial hydrologic system can affect patterns of sliding on other glaciers.

\section{FIELD SITE}

Kennicott Glacier is a $43 \mathrm{~km}$ long alpine, terrestrially terminating glacier in the Wrangell Mountains of southcentral Alaska (Fig. 1). Kennicott Glacier and its tributaries, including Root, Gates and LaChapelle glaciers, cover $413 \mathrm{~km}^{2}$ of a $679 \mathrm{~km}^{2}$ basin. In the vicinity of Hidden Creek Lake $(\mathrm{HCL})$, the glacier is $3 \mathrm{~km}$ wide, and the ice thickness is at least $450 \mathrm{~m}$ (personal communication from E. Pettit, 2010). Surface slopes over the studied reach vary little and are $\sim 0.030 \mathrm{~m} \mathrm{~m}^{-1}$ (Table 1).

Several ice-dammed lake basins adorn the margin of Kennicott Glacier (Fig. 1). Five of these, Jumbo Lake, Donoho Falls Lake (DFL), HCL, Erie Lake and the Gates Lakes (two lakes located within $200 \mathrm{~m}$ of each other), were monitored during 2006. Each of these lakes fills throughout the winter and spring, before draining beneath the glacier sometime during the melt season. Generally, ice-marginal lakes closest to the terminus (e.g. Jumbo Lake) drain first, while lakes at increasing distance from the terminus drain successively later in the melt season (Rickman and Rosenkrans, 1997).

$\mathrm{HCL}$ accepts water from the largest non-glacierized valley draining to Kennicott Glacier, $15 \mathrm{~km}$ from the glacier terminus (Fig. 1). When HCL drains, lake water passes through or beneath the glacier to the terminus. As the flood passes through the subglacial system, down-glacier lake basins such as DFL and Jumbo Lake (both of which have already drained) refill before flooding occurs on the Kennicott River. Although other lakes drain in a similar manner, the annual $\mathrm{HCL}$ outburst flood, or jökulhlaup, is often the only lake drainage event that can be clearly identified in the Kennicott River hydrograph. The jökulhlaup can increase discharge by up to an order of magnitude over non-flood discharge (Rickman and Rosenkrans, 1997; Anderson and others, 2003b; Bartholomaus and others, 2008).

Analyses of water chemistry from around the Kennicott Glacier valley, including time series collected from the Kennicott River, have revealed that solute concentrations in the river vary several-fold over the melt season (Anderson and others, 2003a,b; Bartholomaus and others, 2008). Solutes in the outlet river were almost entirely acquired at the glacier bed and are interpreted to increase with the residence time of water at the bed of the glacier. The water chemistry data support the view that Kennicott River discharge is a dynamic mixture of low-solute water transmitted efficiently through conduits from the glacier

Table 1. GPS site properties

\begin{tabular}{|c|c|c|c|c|c|c|c|}
\hline Receiver & $\begin{array}{c}\text { Distance from } \\
\text { terminus* } \\
\text { km }\end{array}$ & $\begin{array}{c}\text { Elevation on } \\
\text { day } 186 \\
\text { m }\end{array}$ & $\begin{array}{c}\text { Minimum } \\
\text { horizontal speed } \\
\mathrm{m} \mathrm{d}^{-1}\end{array}$ & $\begin{array}{c}\text { Surface slope, } \\
\alpha \\
\mathrm{m} \mathrm{m}^{-1}\end{array}$ & $\begin{array}{l}\text { Glacier } \\
\text { width } \\
\text { m }\end{array}$ & $\begin{array}{c}\text { Thickness } \\
\text { estimate } 1^{\dagger} \\
\mathrm{m}\end{array}$ & $\begin{array}{c}\text { Thickness } \\
\text { estimate } 2^{\dagger} \\
\mathrm{m}\end{array}$ \\
\hline GPS1 & 5.49 & 649.3 & 0.14 & 0.037 & 4420 & 550 & 400 \\
\hline GPS2 & 8.29 & 740.4 & 0.18 & 0.027 & 3290 & 860 & 680 \\
\hline GPS3 & 11.10 & 810.7 & 0.21 & 0.026 & 2960 & 1020 & 800 \\
\hline GPS4 & 15.04 & 917.2 & 0.29 & 0.027 & 3710 & 970 & 770 \\
\hline GPS5 & 18.58 & 1015.2 & 0.34 & 0.028 & 3420 & 1080 & 820 \\
\hline
\end{tabular}

\footnotetext{
*Measured along glacier center line.
}

${ }^{\dagger}$ Calculated using Equation (7). Estimate 1 assumes a parabolic glacier cross section and that the minimum horizontal speed is entirely due to viscous deformation. Estimate 2 makes the same assumption about glacier cross section but assumes that deformation makes up half the minimum horizontal speed and steady basal motion makes up the other half. 
surface and margins, and high-solute water that experienced longer contact times with rock at the bed in linked cavities (Anderson and others, 2003a).

In 2000 and 2006 field campaigns to Kennicott Glacier, the dynamic response of the glacier to the HCL jökulhlaup has been documented (Anderson and others, 2005; Bartholomaus and others, 2008). In both instances, the glacier reached anomalously high speeds during the drainage of $\mathrm{HCL}$. Thus, the drainage of $\mathrm{HCL}$ represents a natural experiment that serves as a probe of the glacier response to a transient hydrologic event.

\section{FIELD METHODS}

We made direct measurements of ice surface motion and direct and indirect measurements of water in, under and around Kennicott Glacier from day of year 132 (12 May 2006) to day 230 (18 August 2006).

\subsection{GPS documentation of ice motion}

In the spring and early summer, we deployed five GPS units spaced evenly over $12.5 \mathrm{~km}$ of the ablation area center line, the topmost site being up-glacier from HCL (Fig. 1). Each Trimble Zephyr Geodetic antenna was attached to a triangular base fixed to a tripod of $3 \mathrm{~m}$ electrical conduit steam-drilled into the ice surface in the manner of Anderson and others (2004). Data were recorded on Trimble 5700 receivers at $15 \mathrm{~s}$ intervals. Over the course of the summer, each GPS station needed to be re-drilled into the ice following significant ablation. During re-drills, local glacier velocities were extrapolated from those before and after the re-drill. During one of these reinstallations, on day 171, GPS3 was relocated $725 \mathrm{~m}$ to the west-northwest of its initial position, to place it more in line with the other receivers. It is this second position that is illustrated In Figure 1. A sixth GPS system, $1.5 \mathrm{~km}$ south of the glacier terminus, served as a base station for differential processing of GPS baselines. Table 1 describes aspects of each on-ice GPS site.

During post-processing, 24 hour files were broken into 1 hour increments and differentially, statically, processed using Trimble Geomatics Office and kinematically processed using the GIPSY software package from the NASA Jet Propulsion Laboratory (Gregorius, 1996). Both processing routines revealed similar patterns of motion; Trimble Geomatics Office solutions are plotted in all figures. With a coordinate rotation, we separated the GPS displacements into along-mean-flow and across-mean-flow components. The standard deviation of horizontal, across-flow positions during periods with minimal high-frequency velocity fluctuations is $\sim 3 \mathrm{~mm}$ for the majority of our time series, half the hourly displacement for one of our slower-moving GPS stations. However, on day 191, the GPS base station began to lose power intermittently (usually at night), increasing the standard deviation of our horizontal position solutions to $60 \mathrm{~mm}$. Therefore, in order to ease the interpretation of velocity fluctuations over periods of several hours and longer, we smoothed our entire horizontal position time series with the robust locally weighted scatter-plot smoothing algorithm, rloess, implemented with the software package MATLAB ${ }^{\text {TM }}$ (v. 7.9) (Truffer and others, 2009). We used a 1 day smoothing window that preserved velocity fluctuations with periods greater than several hours but eliminated fluctuations with higher frequencies. The 1 day smoothing window has the potential to reduce the magnitude of the diurnal fluctuations by $25 \%$ when compared with a 0.5 day smoothing window. This smoothing algorithm allows us to describe the horizontal velocity of Kennicott Glacier between days 191 and 229, data we have not been able to present in previous work (Bartholomaus and other, 2008).

Ice surface slope at the GPS receivers ranged from 0.026 to $0.037 \mathrm{~m} \mathrm{~m}^{-1}$ (Table 1); if mean ice motion is surfaceparallel, then any bed-parallel horizontal motion will result in lowering of the GPS antenna. We remove this vertical component of surface parallel motion from the vertical displacement records of each GPS receiver, and refer to the remainder of the vertical record as the 'slope-corrected vertical displacement' (Figs 2c and 3c). The vertical positions calculated without a base station (days 191-229) exhibit a clear bias towards lower elevations; thus, the smoothing algorithm could not be used for these vertical position data. We have shaded these positions more lightly when plotting them in Figure 2.

\subsection{Measurements of glacier hydrology}

Measurements relevant to glacier hydrology consisted of stage, water and air temperature, and water chemistry. The HCL and DFL stage sensors were installed $\sim 70$ and $\sim 30 \mathrm{~m}$ above their respective lake bottoms. The depth of Erie Lake is unknown, but the stage sensor was likely placed on the order of $50 \mathrm{~m}$ above the lake bottom. On day 159, after DFL drained following its monotonic spring and early-summer filling, the DFL sensor was relocated to the bottom of the empty basin in anticipation of refilling during the HCL flood. A temperature sensor in Jumbo Lake recorded the presence or absence of water. Each of these sensors recorded data every $10 \mathrm{~min}$.

A sonic ranging sensor was fixed to the west footbridge over the Kennicott River to measure stage every $15 \mathrm{~min}$. The cross section of the Kennicott River did not change significantly between 1999/2000 field seasons (Anderson and others, 2003b) and the HCL jökulhlaup of 2006. After the 2006 jökulhlaup, the largest maximum discharge in 10 years, we resurveyed the river cross section. During the $\sim 24$ hours of elevated discharge, the river scoured up to $3 \mathrm{~m}$ in the thalweg (deepest portion of the channel cross section). Thus, we calculated separate rating curves for the pre- and post-jökulhlaup portions of our record and transitioned smoothly between them with an arctangent function. Both rating curves are set by logarithmic velocity profiles (Julien, 1995, p. 94) from which we calculate a depth-averaged velocity for various portions of the channel and sum the velocity-depth-width products to calculate the total discharge through the river channel. This method requires estimation of a channel bed roughness height; we use the 84th percentile boulder size, $D_{84}$, observed during low flows to estimate the roughness height, $z_{0}=D_{84} / 10$. These steps reproduce the rating curve developed during the 1999 and 2000 field campaigns by actual discharge measurements, and allow a smooth transition through the flood to a new rating curve that pertains to the remainder of the season.

Near the same footbridge where stage was measured, we also measured water electrical conductivity (abbreviated as conductivity) and temperature. Outlet water chemistry was further assessed with near-daily sampling at the location of the conductivity/temperature probe. We filtered our samples in the field $(<0.45 \mu \mathrm{m})$ and later analyzed them for $\mathrm{Cl}^{-}, \mathrm{NO}_{3}{ }^{-}$ and $\mathrm{SO}_{4}{ }^{2-}$ concentrations. 

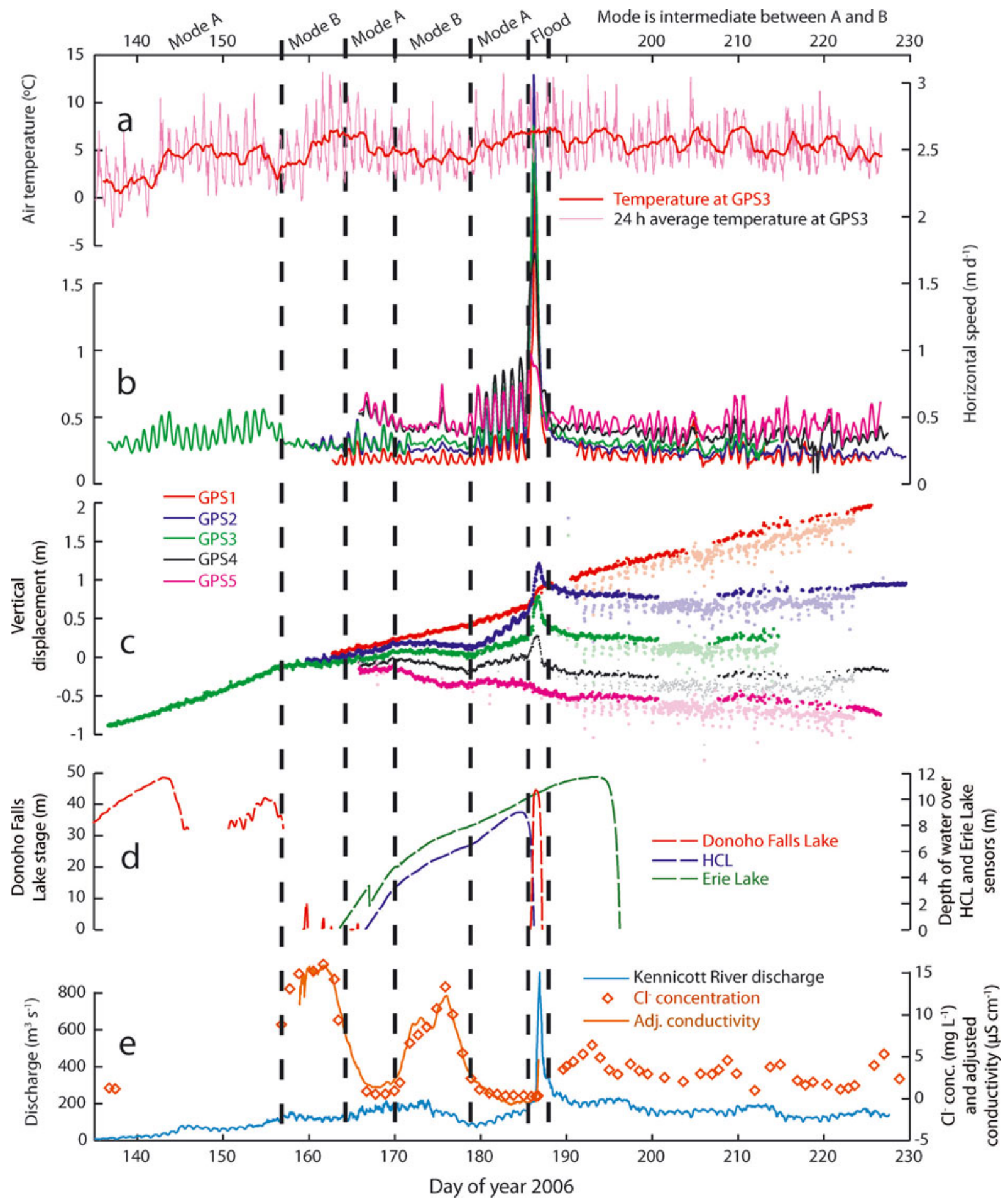

Fig. 2. Time series of data collected during the 2006 field season. Prior to day 188, vertical dashed lines identify two distinct glacier Modes, A and B. After day 188, Mode switches are indistinct. (a) Half-hour and 24 hour running average air temperature at GPS3. (b) Horizontal ice surface speeds calculated using smoothed displacements at each GPS receiver. Due to collapse of the GPS3 support platform, data for this receiver are not plotted after day 210. (c) Slope-corrected vertical displacement (displacement minus the surface-parallel trajectory) at each GPS receiver. During the failure of our base station (days 191-226), some vertical positions exhibit a clear negative bias. These positions are lightly colored. (d) Lake level record at DFL, HCL and Erie Lake. DFL stage is relative to the lake basin floor. HCL and Erie Lake stage are with reference to the stage at time of instrument deployment. Total $\mathrm{HCL}$ depth was $\sim 80 \mathrm{~m}$. The depth of Erie Lake is not known. (e) Discharge, $\mathrm{Cl}^{-}$ concentration and adjusted electrical conductivity of the Kennicott River. We linearly adjusted the value of the electrical conductivity so that it plots on the same axis as the $\mathrm{Cl}^{-}$concentration. Adjusted conductivity = conductivity/7.41-7.00.

Air temperature was recorded by radiation-shielded sensors $0.5-0.7 \mathrm{~m}$ above the ice surface at GPS1-GPS3 at 10 or $30 \mathrm{~min}$ intervals. We measured ablation at the support poles of each GPS station at irregular intervals ranging from 3 to 40 days.

\section{RESULTS OF 2006 FIELDWORK}

We begin by describing the salient features of each of our several-month time series. However, as the drainage of $\mathrm{HCL}$ profoundly affects each of our time series over a several-day period, we discuss all observations surrounding 


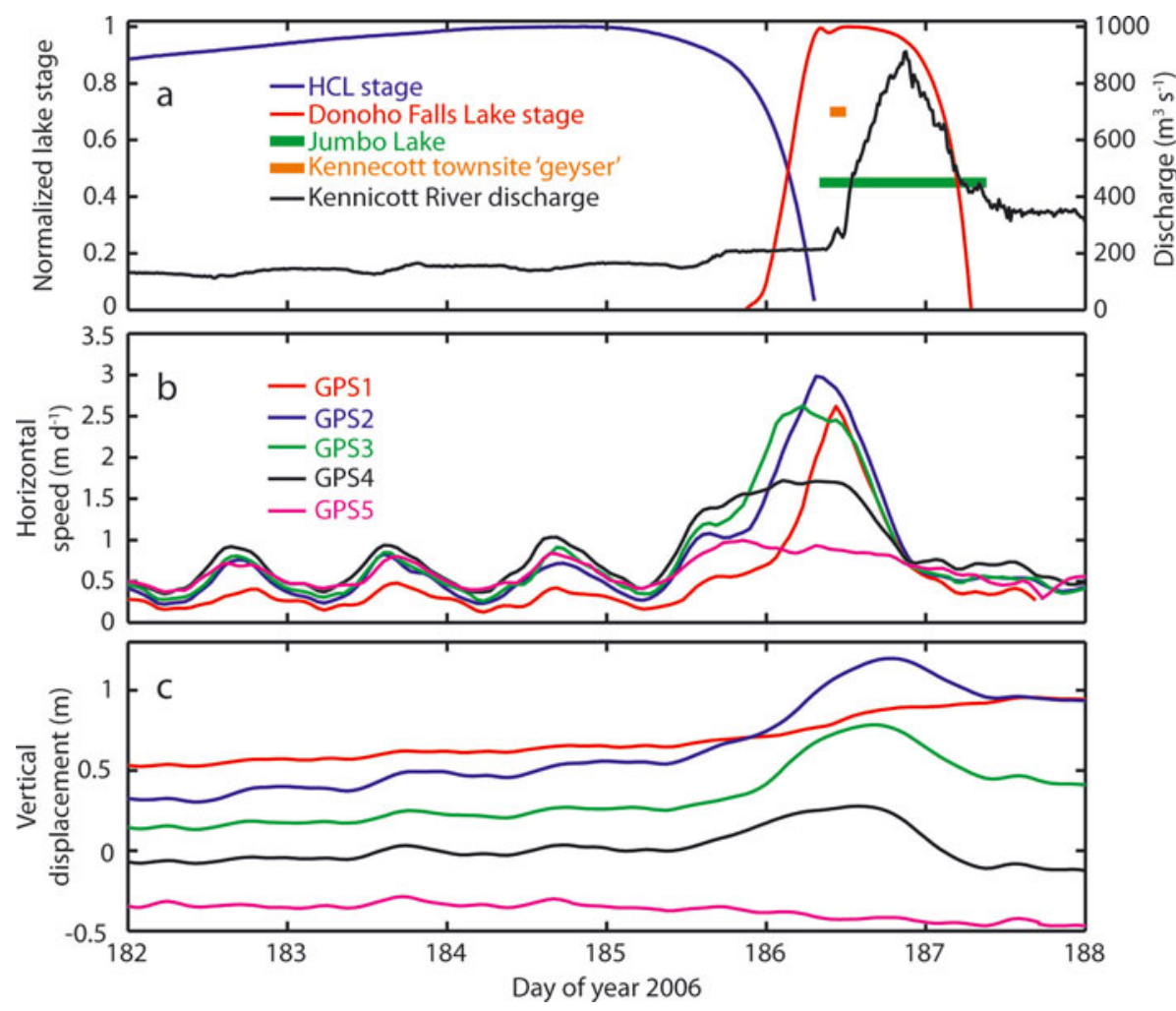

Fig. 3. Detail of observations during period immediately before and during the drainage of HCL. (a) Hydrology records showing HCL and DFL stage, Kennicott River discharge, and status of Jumbo Lake and a supraglacial 'geyser' observed near the Kennecott town site. The symbols for Jumbo Lake and the 'geyser' represent only the periods when they were full or active, respectively; no information exists about their stage or discharge. (b) Horizontal ice surface speeds at each GPS receiver. To allow for the resolution of higher-frequency changes in motion, the smoothing window used to filter the positions for the speed calculation of (b) is half the duration of that used for Figure $2 \mathrm{~b}$. (c) Slope-corrected vertical displacement of each GPS receiver, smoothed in the same manner as (b).

the lake drainage and consequent jökulhlaup together, in Section 4.6.

\subsection{Ice motion}

Horizontal ice displacement reflects two types of motion: a steady, background component, and an unsteady component that varies on diurnal and seasonal timescales. Over our study area, the magnitude of the steady speed increases with distance from the glacier terminus (Table 1), whereas the magnitude of higher-frequency speed fluctuations is independent of position on the glacier. It is these fluctuations that we focus on.

Over the 61 (GPS5) to 91 day (GPS3) records, instantaneous (mean hourly) horizontal ice surface speeds ranged between 0.14 and $0.95 \mathrm{~m} \mathrm{~d}^{-1}$ during non-jökulhlaup times, and are generally well correlated with each other (Fig. 2b). Average rates of surface horizontal motion over the entire period of observation range between $0.24 \mathrm{~m} \mathrm{~d}^{-1}$ (GPS1, for 62.8 days) and $0.47 \mathrm{~m} \mathrm{~d}^{-1}$ (GPS5, for 60.8 days).

Diurnal variations in the horizontal speed with amplitudes of up to $0.5 \mathrm{~m} \mathrm{~d}^{-1}$ are present in portions of each of the five GPS records, although they are absent or quite weak at other times. The strength of the diurnal variation may be described by its diurnal velocity ratio: the range of the daily speed divided by the minimum speed for the day. This ratio is analogous to the percent speed-up sometimes used to describe the impact of surface water delivery on glacier flow (e.g. Bartholomew and others, 2010). Prior to the jökulhlaup, the diurnal velocity ratio tended to vary in blocks of time with generally higher and lower values
(Fig. 4b). The switches between time intervals with high and low diurnal velocity ratios occurred nearly synchronously across the instrumented reach of the glacier; we refer to these time periods as Mode A and Mode B (Bartholomaus and others, 2008). Periods with strong diurnal velocity variations (e.g. diurnal velocity ratios greater than 0.4) are referred to as Mode A, whereas Mode $\mathrm{B}$ is characterized by smaller diurnal velocity ratios. The highest diurnal velocity ratios not coincident with the jökulhlaup immediately precede the drainage of $\mathrm{HCL}$, from day 178 to day 186, when they reach values between 2.4 (at GPS2; Fig. 4b) and 1.6 (at GPS1; not shown). Typical diurnal velocity ratios during Mode $B$ (e.g. between days 172 and 178) are $<0.3$. Following the jökulhlaup, the diurnal velocity ratio is more consistent and close to 0.3 ; they lack both the highest or lowest values present during the period before the jökulhlaup.

Uplift rate, following Iken and others (1983), is the rate of change of slope-corrected vertical displacement. Maximum uplift rate (slopes of vertical displacement time series; Figs 2c and 3c) coincided with maximum horizontal speed (Figs 2b and 3b); thus generally Mode A is associated with positive uplift rate, whereas Mode $B$ is marked by zero or negative uplift rate. Until day 170, each GPS receiver recorded increases in slope-corrected vertical displacement. GPS3, the earliest installed receiver, rose (against its surface slope) at an average rate of $0.036 \mathrm{~m} \mathrm{~d}^{-1}$ from day 136 until day 157, after which uplift rate decreased but remained positive. From day 170 until days 178-179, GPS2-GPS5 fell (i.e. negative uplift rate) (Mode B). The 


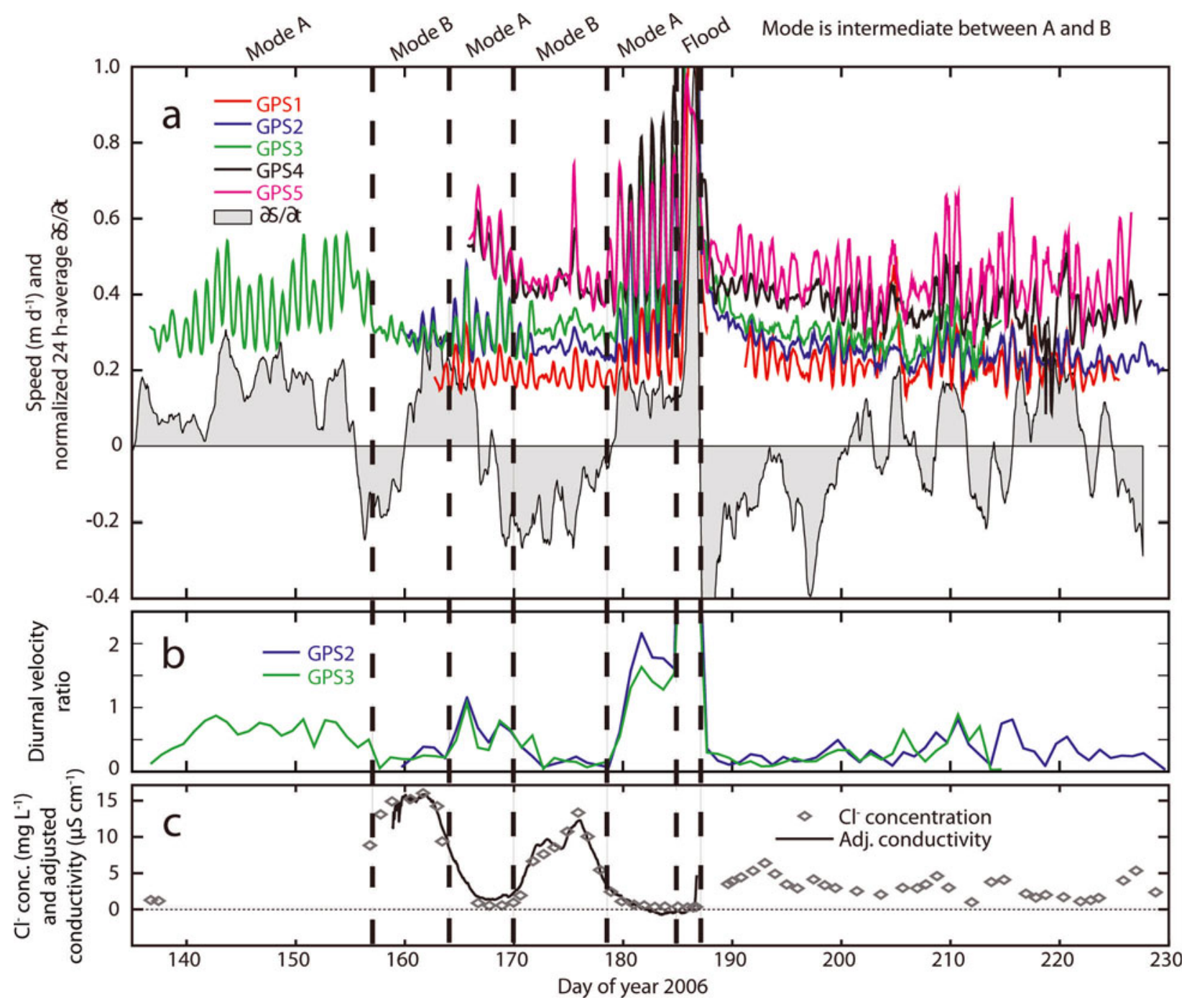

Fig. 4. (a) Time series of normalized $\partial S / \partial t$ and non-normalized horizontal speed at GPS receivers, as in Figure $2 \mathrm{~b}$. Speeds greater than $1 \mathrm{~m} \mathrm{~d}{ }^{-1}$ are not shown. (b) Diurnal velocity ratio for each day in our time series at two representative GPS stations. GPS2 reaches a maximum diurnal velocity ratio of 8.6 on day 185 . Also on day 185 , GPS3 reaches a maximum ratio of 5.4. (c) $\mathrm{Cl}^{-}$concentration and adjusted electrical conductivity, as in Figure 2e.

receivers showed renewed positive uplift rates from day 178-179 up to the drainage of HCL (Mode A). In contrast, GPS1 experienced nearly steady uplift rates for the entirety of its record, punctuated only by increased uplift rates during the drainage of HCL. After the drainage of $\mathrm{HCL}$, GPS1 resumed the steady climb it had recorded prior to day 186. Several days after the jökulhlaup, on day 191, GPS2-GPS5 resumed moving roughly parallel to the ice surface for the remainder of the measurement period. Net slope-corrected vertical displacement over the measurement period ranged from $-0.70 \mathrm{~m}$ (GPS5, over 60.2 days) to $2.00 \mathrm{~m}$ (GPS1, over 62.9 days).

\subsection{Kennicott River discharge record}

As is typical of other glacier-fed rivers, the Kennicott River discharge fluctuated at several timescales (Figs 2e and 3a) (e.g. Anderson and others, 1999). Discharge increased from a few $\mathrm{m}^{3} \mathrm{~s}^{-1}$ when the winter ice broke out on day 130 to a summer mean of $150 \mathrm{~m}^{3} \mathrm{~s}^{-1}$ by day 157 . For the remainder of the summer, with the exception of the HCL jökulhlaup, discharge varied between $\sim 100$ and $250 \mathrm{~m}^{3} \mathrm{~s}^{-1}$. Discharge also varied diurnally with an amplitude of $10 \mathrm{~m}^{3} \mathrm{~s}^{-1}$, roughly half a day out of phase with air temperature on the glacier.
The jökulhlaup observations are discussed in greater depth below, along with other related observations.

\subsection{Water chemistry}

Solute concentrations in the Kennicott River vary significantly over the period of observation. The concentration of $\mathrm{Cl}^{-}$ranged from 0.26 to $16.03 \mathrm{mg} \mathrm{L}^{-1}$, and tracks well with conductivity (Fig. 2e). Winter snowfall collected on day 134 from Root Glacier had $0.07 \mathrm{mg} \mathrm{L}^{-1} \mathrm{Cl}^{-}$, whereas Jumbo Creek carried $0.11 \mathrm{mg} \mathrm{L}^{-1} \mathrm{Cl}^{-}$, at base flow on day 229. This provides further evidence, as had been found before, that $\mathrm{Cl}^{-}$ in the Kennicott River comes not from snowfall and associated runoff, but from the glacier bed (Anderson and others, 2003a,b). Prior to the HCL jökulhlaup, $\mathrm{Cl}^{-}$concentration in the river can be described as low or high $\left(<3 \mathrm{mg} \mathrm{L}^{-1} \mathrm{Cl}^{-}\right.$or $>5 \mathrm{mg} \mathrm{L}^{-1} \mathrm{Cl}^{-}$), and switched rapidly between these levels, roughly synchronized with the Mode A/B switches of the horizontal velocity record. After the jökulhlaup, $\mathrm{Cl}^{-}$concentrations were less variable, at levels between the highs and lows measured earlier.

Electrical conductivity followed similar patterns until the jökulhlaup, when the conductivity sensor cable was severed and the sensor was lost. Low values of conductivity were 
within the range $50-70 \mu \mathrm{sm}^{-1}$ and higher values ranged between 115 and $170 \mu \mathrm{sm}^{-1}$ (Fig. 2e). Low conductivity and $\mathrm{Cl}^{-}$concentrations coincide with Mode A; higher values coincide with Mode B.

\subsection{Lake level records}

The ice-dammed lakes along the margin of Kennicott Glacier offer an important tool for assessing glacier hydrology (Figs $2 \mathrm{~d}$ and $3 \mathrm{a}$ ). The timing of their annual springsummer drainage allows one to track qualitatively the development and up-glacier propagation of a highdischarge, low-pressure conduit (Anderson and others, 2003b; Kessler and Anderson, 2004). Once a lake empties, its basin is generally well connected to the subglacial hydrologic network and can therefore serve as a manometer during high subglacial water-pressure events (Anderson and others, 2003b). After filling through the spring, Jumbo Lake drained between days 148 and 151. The DFL pressure logger recorded a complicated series of fillings and drainings between day 143 , when the level first fell significantly, and day 166, when the lake drained for the last time of the summer (excepting the $\mathrm{HCL}$ flood on day 186). $\mathrm{HCL}$ and Erie Lake began to drain on days 184 and 190, respectively; the draining of HCL resulted in the jökulhlaup. The Gates Lakes remained full throughout the observation period.

\subsection{Weather records}

Air temperatures at GPS1-GPS3 were quite similar and generally followed the same seasonal patterns. At GPS3, $90 \%$ of temperature readings were between $2{ }^{\circ} \mathrm{C}$ and $11^{\circ} \mathrm{C}$, although air temperature prior to day 160 occasionally fell below $0^{\circ} \mathrm{C}$ (Fig. 2a). Ablation rates varied between 0.038 and $0.087 \mathrm{~m} \mathrm{~d}^{-1}$, with higher rates at lower elevations. The mean, midsummer ablation rate at GPS3 was $0.062 \mathrm{~m} \mathrm{~d}^{-1}$.

Precipitation totaled $158 \mathrm{~mm}$ between days 132 and 230 at the National Weather Service McCarthy 3 SW weather station. The most intense storm brought $2.5 \mathrm{~cm}$ of rain during day 172-173. Neither this rain event, nor any other during the summer, had any discernible impact on glacier motion.

\subsection{Response to the Hidden Creek Lake jökulhlaup}

One of the primary draws to study ice motion and subglacial hydrology on Kennicott Glacier is the natural experiment performed annually when HCL drains 20$30 \times 10^{6} \mathrm{~m}^{3}$ of water beneath the glacier over $\sim 3$ days. On day 186 (5 July 2006), the first day of the HCL jökulhlaup, horizontal ice surface speeds reached maxima of $3.0 \mathrm{~m} \mathrm{~d}^{-1}$, up to six times greater than mean speeds recorded during non-flood times (Fig. 3). At the time of $\mathrm{HCL}$ drainage initiation late on day 184 , both Jumbo Lake and DFL basins were empty, with streams passing along their bottoms to enter tunnel mouths in Root Glacier. During the passage of jökulhlaup floodwaters through Kennicott Glacier, both of these lake basins filled for 24-30 hours before re-draining beneath the ice. In 2000 and 2006, discharge of the streams into the drained basins and chemistry of the water that filled the basin indicated that DFL filled with water emerging from the glacier during the jökulhlaup (Anderson and others, 2003a).

On day 185 , as the discharge from $\mathrm{HCL}$ was increasing but the Kennicott River had yet to flood significantly, each GPS receiver accelerated. The most pronounced responses were recorded below $\mathrm{HCL}$, where in quick succession GPS3 speeded up, then GPS2 and finally GPS1. This wave of acceleration progressed down-glacier at an average speed of $1.3 \mathrm{~km} \mathrm{~h}^{-1}$. Peak speed occurred in the same order: GPS3 first, followed by GPS2 and then GPS1. The responses of the two receivers at and above HCL (GPS4 and GPS5) were more muted, with only minor increases in speed above typical diurnal maxima at GPS5. Each GPS receiver attained a maximum speed of 1.2 (GPS5) to $3.0 \mathrm{~m} \mathrm{~d}^{-1}$ (GPS1-GPS3). Speeds began to decline simultaneously around day 186.3, falling back towards pre-flood rates of $0.2-0.8 \mathrm{~m} \mathrm{~d}^{-1}$.

In contrast to the horizontal speeds, for which the most significant jökulhlaup response was at GPS1-GPS3, GPS2GPS4 experienced the most pronounced rapid increases in slope-corrected vertical displacement, up to a total of $0.55 \mathrm{~m}$ at GPS2 (Fig. 3c). There appear to be two phases to the jökulhlaup-related uplift history of GPS2-GPS4. The initial rate of uplift at day 185.5 was slow for each of these receivers. At day 186.1, the rate of uplift at GPS2 and GPS3 increased to $0.72 \mathrm{~m} \mathrm{~d}^{-1}$, but declined slightly at GPS4. The timing of the maximum uplift varied slightly between stations (from day 186.5 to 186.8 ) and was attained earliest at up-glacier sites. The greatest horizontal speed coincided with the greatest uplift rate (Fig. 3). Initiation of collapse occurs first at GPS4 and progresses down-glacier. At GPS4 through GPS2, following the peak in uplift, roughly a day of high vertical relaxation rates (at roughly $-0.50 \mathrm{~m} \mathrm{~d}^{-1}$ ) is followed by significantly slower collapse until day 191 .

The vertical response of GPS1 appears as a step of $0.20 \mathrm{~m}$ set within the otherwise steady rate of background uplift. This was accomplished by enhanced uplift rate of $0.27 \mathrm{~m} \mathrm{~d}^{-1}$ that lasted from day 186.0 to 186.7 , roughly coincident with the time of the greatest uplift rate at GPS2GPS4. GPS5, $3 \mathrm{~km}$ up-glacier of HCL, displayed little or no vertical response that can be clearly attributed to the $\mathrm{HCL}$ flood. This most up-glacier receiver maintains a nearly steady negative uplift rate, falling $0.20 \mathrm{~m}$ between days 185 and 191.

The onset of horizontal deceleration towards baseline ice speeds coincided with the onset of the rapid increase in discharge of the Kennicott River. The flood peaked at $900 \mathrm{~m}^{3} \mathrm{~s}^{-1}$ at day 186.9 , before declining exponentially over $\sim 4$ days back toward pre-flood discharges. The timing of down-glacier lake filling and draining is also closely associated with ice speed. The linear rising limb of DFL stage during the jökulhlaup nearly perfectly coincides with the rise of speed at the closest GPS receiver, GPS2. DFL stage and GPS2 speed peaked simultaneously. However, although ice at GPS2 began to decelerate shortly after attaining its maximum speed, DFL stage remained high, up to $45 \mathrm{~m}$ above its basin floor, until Kennicott River discharge began to decline from its maximum. Based upon our temperature logger record, Jumbo Lake began to fill 0.5 days after upglacier DFL, and drained only 0.1 days after DFL drained.

As yet another proxy for water pressure in the glacier during the outburst flood, a supraglacial 'geyser', several meters in height above the ice surface, was observed between days 186.4 and 186.5 several hundred meters west of the town site of Kennecott (personal communication from N. Bay, 2006).

\section{MODEL OF FEEDBACKS BETWEEN WATER STORAGE AND BASAL MOTION}

Diurnal surface velocity fluctuations that increase and decrease in strength are a common feature of glaciers (e.g. 
Anderson and others, 2004; Sugiyama and Gudmundsson, 2004; Sugiyama and others, 2007; Truffer and others, 2009; Shepherd and others, 2009) and, where present, range from $10 \%$ of the diurnal minima to five times the minima (diurnal velocity ratio $0.1-5)$. Indeed, variations in the strength of the diurnal velocity fluctuations (i.e. the magnitude of the diurnal velocity ratio) are one of the most striking patterns in the Kennicott Glacier GPS data. We have referred to the distinct, repeating patterns of stronger and weaker diurnal velocity fluctuations as Mode A and Mode B, respectively (Bartholomaus and others, 2008).

Synchronous tracking of basal water pressure and velocity on other glaciers has revealed the important role that glacier hydrology has in controlling velocity fluctuations. For example, on Lauteraargletscher, diurnal surface velocity fluctuations are present throughout much of the 2001 summer; however, when daily-averaged borehole water levels began to fall in early July, the diurnal velocity fluctuations vanished (Sugiyama and Gudmundsson, 2004). Based on this and other examples in the literature, we hypothesize that diurnal surface velocity fluctuations that appear and disappear over a season are likely common in alpine glaciers and can serve as a probe of the evolving subglacial hydrologic system. Numerical models that attempt to predict basal motion must therefore be able to reproduce these observations. We next describe one such model.

\subsection{Conceptual model}

Our conceptual model (Bartholomaus and others, 2008) is similar to that used to explain observations at Haut Glacier d'Arolla (Hubbard and others, 1995; Mair and others, 2002) and Aletschgletscher, Switzerland (Hock and others, 1999). We focus on the daily-averaged rate of change of water volume stored within the glacier, 24 hour averaged $\partial S / \partial t$, as it allows us to discern broader temporal patterns of water storage, beyond the daily fluctuations driven by diurnal melt variability. We interpret a positive 24 hour averaged $\partial S / \partial t$ as indicating that the subglacial hydrologic system is not of sufficient capacity to transmit the water delivered to it from the glacier surface or margins. Therefore, when the instantaneous $\partial S / \partial t$ is positive, the increasing stored water must be englacial (Mode A). Englacial water, in macroporous moulins and crevasses, exerts a pressure on the bed, reducing the effective ice pressure at the bed. The effective pressure affects glacier basal motion through an inverse power-law relationship (e.g. Bindschadler, 1983), which feeds back on the englacial water storage by opening up space at the glacier bed into which englacial water is drawn. This dynamic subglacial storage is often considered to be cavities in the lee of bedrock bumps or asperities, although basal crevasses are also possible (Harper and others, 2010).

In this conceptual model, the state of the subglacial hydrologic system is of paramount importance in setting the basal motion response to changes in water supply: the glacier response to the input of water cannot be predicted without knowing the condition of the subglacial hydrologic system. In the present study, we use the 24 hour averaged $\partial S /$ $\partial t$ as a proxy for this condition, and see good correspondence between positive 24 hour averaged $\partial S / \partial t$ and Mode A behavior (Fig. 4a). Only when the 24 hour averaged $\partial S / \partial t$ is positive will instantaneous increases in $\partial S / \partial t$ lead to increased basal motion and to surface motion above the background rate.

\subsection{Model development}

We explore the above conceptual model by recreating the systems and interactions outlined above in a numerical model. A sketch of our model is as follows, with the complete description of the model numerics following thereafter. A key feature of the model is the presence of two water reservoirs within the glacier. Water supplied to the glacier surface or sides fills a subglacial reservoir with dynamic capacity. Water beyond the volume of the subglacial reservoir fills an englacial reservoir that has static macroporosity and is well connected to the bed. The basal water pressure scales linearly with the volume of englacial water storage and this basal water pressure in turn controls the rate of basal motion. Any increases in basal motion can expand the volume of the subglacial reservoir, thereby drawing water down out of the englacial reservoir, exerting a negative feedback on basal motion. Here we envision a subglacial network of interconnected cavities, formed in the lee of bedrock bumps, which grow as a result of basal motion and collapse due to viscous creep. In reality, the exact mechanism by which water travels and is stored at the glacier bed is less important than the characteristic that increasing basal motion increases the available basal storage, a situation applicable to both hard- and soft-bedded glaciers.

To capture the essence of the velocity response to changing hydrology, we make several simplifying assumptions: that the hydrologic system is uniform across the glacier and that the water pressure in subglacial conduits does not significantly affect basal sliding. Other models (e.g. Clarke, 2003; Kessler and Anderson, 2004; Pimentel and others, 2010; Schoof, 2010) have successfully predicted the patterns of water pressure and ice motion observed at other glaciers without assuming uniformity. We, however, use mean water pressures in the glacial hydrologic system, aware that in reality they are spatially variable no doubt on several length scales. Although others have shown this is rarely the case (e.g. Fudge and others, 2005), for most of our period of observation the instrumented reach of glacier operates in synchrony (as reflected in switches between Mode A and B states shown in Figure 2). We therefore treat the study reach of the glacier as a single, homogeneous slab, with no spatial variability in either the water balance or the control that water pressure exerts on basal motion. While we lose the opportunity to investigate the phasing among sites on the glacier, we gain the constraint of a water balance applicable to the entire instrumented reach.

Linked cavities are expected to cover much of a glacier's bed. When supplied with water at a sufficient rate, pressurization of water in this linked cavity system can promote basal motion (e.g. Kamb, 1987; Anderson and others, 2004). For this reason, our model focuses exclusively on cavity evolution, to the exclusion of conduits or water storage in any basal till. In our model, cavities grow by basal sliding and by melt, and collapse by viscous deformation of their ice roofs, which in turn is dependent on the effective pressure at the bed.

The model glacier is a rectangular prism with dimensions $L \times W \times H$ chosen to approximate the instrumented reach of Kennicott Glacier, with sides of 15, 4 and $0.4 \mathrm{~km}$ respectively. The model glacier bed is given a uniform distribution of identically sized cavities, each reacting in the same way to the evolution of water storage. Following Kessler and Anderson (2004), bedrock bumps are assumed to be $h$ tall, $w_{\mathrm{c}}$ wide, and are spaced $\lambda_{x}$ and $\lambda_{y}$ in down-glacier and 
cross-glacier directions, respectively. Effectively, $\lambda_{x}$ and $\lambda_{y}$ define a unit cell of the bed (Fig. 5), containing one bedrock bump. One may define a dimensionless cavity-forming capacity of the glacier bed $f=\left(h w_{\mathrm{c}} / \lambda_{x} \lambda_{y}\right)$. In the simulations to follow, our cavities are spaced evenly with $\lambda_{x}=10 \mathrm{~m}$ and $\lambda_{y}=10 \mathrm{~m}$; each cavity has width $w_{\mathrm{c}}=5 \mathrm{~m}$, and height $h=1 \mathrm{~m}$ at the right-angled lip where ice decouples from the bump; hence $f=0.05$.

At each model time-step, subglacial storage, $S_{\text {sub, }}$ calculated as the available cavity volume, is filled from the total volume of storage. The remainder of the total storage is englacial, $S_{\text {en }}$. We assume the glacier has a macroscale, effective porosity, $\phi$, that is well connected to the subglacial cavity reservoir. In reality, crevasses and moulins are present on the surface of Kennicott Glacier in distinct bands. We are aware of at least two such bands, in the vicinity of GPS2 and GPS4. Given the connected porosity $\phi$, englacial water rises above the glacier bed to a height $z_{\mathrm{w},}$ similar to water rising in piezometers tapping a confined aquifer:

$$
z_{\mathrm{w}}=\frac{S_{\mathrm{en}}}{L W \phi} .
$$

The effective pressure, $N$, is then the ice overburden pressure less the englacial water pressure:

$$
N=\rho_{\mathrm{i}} g H-\rho_{\mathrm{w}} g z_{\mathrm{w}}
$$

where $\rho_{\mathrm{i}}$ and $\rho_{\mathrm{w}}$ are the densities of ice and water, respectively, $H$ is the ice thickness and $g$ is the acceleration due to gravity.

We assume that the glacier slides according to a powerlaw relationship (e.g. Bindschadler, 1983),

$$
u_{\mathrm{b}}=\frac{C \tau_{\mathrm{b}}{ }^{n}}{N \gamma},
$$

where $u_{\mathrm{b}}$ is the basal velocity, $C$ and $\gamma$ are parameters, $\tau_{\mathrm{b}}$ is the basal shear stress and $n$ is the flow-law exponent. Although there are limitations to this sliding law, we (as well as other authors: e.g. Vieli and others, 2001; Schoof, 2010) prefer the formulation in Equation (3) due to its simplicity and its continued success in describing observations across a number of different glaciers (e.g. Iken and Bindschadler, 1986; Sugiyama and Gudmundsson, 2004). The sensitivity of this model to the three parameters $\gamma, C \tau_{\mathrm{b}}{ }^{n}$ and $\phi$ is discussed in Section 5.5. Sensitivity to the cavity-forming capacity, $f$, is addressed in Section 6.2.

A representative cavity cross-sectional area, $A_{c}$, increases at a rate governed by the sliding speed and the melt rate of cavity walls, and declines at a rate governed by creep closure (Nye, 1976):

$$
\frac{\mathrm{d} A_{\mathrm{c}}}{\mathrm{d} t}=u_{\mathrm{b}} h+\left(1-\gamma_{\mathrm{R}}\right)\left(\frac{\rho_{\mathrm{w}} g}{\rho_{\mathrm{i}} L_{\mathrm{f}}}\right)\left(\frac{\lambda_{x}}{W} Q_{\text {out }}\right) \nabla z_{\mathrm{w}}-2 A A_{\mathrm{c}}\left(\frac{N}{n}\right)^{n},
$$

where $\gamma_{R}$ is Röthlisberger's dimensionless constant (0.313) (Röthlisberger, 1972; Kessler and Anderson, 2004), $L_{\mathrm{f}}$ is the latent heat of fusion of ice, $\left(\frac{\lambda_{X}}{W} Q_{\text {out }}\right)$ is the water outflow discharge per cavity in a transverse section of our model $\left(Q_{\text {out }}\right.$ is the Kennicott River discharge (Fig. 2e)), $\nabla z_{\mathrm{w}}$ is the hydraulic gradient across a cavity and $A$ is Glen's flow-law parameter. We take $\nabla z_{\mathrm{w}}$ as the glacier surface slope divided by the cavity network sinuosity, assumed to be 3 (Kessler and Anderson, 2004). The first term in Equation (4) represents the growth due to sliding, the second term represents the growth

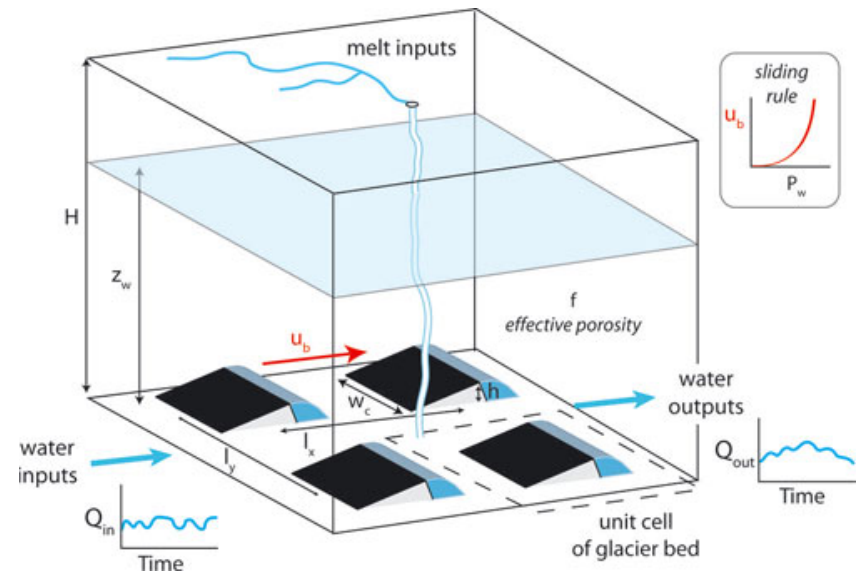

Fig. 5. Schematic of a representative portion of the model domain, in which the glacier bed is characterized by a set of bedrock bumps that serve to nucleate cavities. A unit cell of the glacier bed consists of one bump and its associated cavity, centered in a domain of width $\lambda_{y}$ and length $\lambda_{x}$. Spacing between the bumps, the widths, and the heights of the bumps govern the cavity-generating capacity of the bed. Changes in total storage of water within the glacier system are governed by differences in the time series of water inputs through surface melt and through drainage of side-glacier lakes, $Q_{\mathrm{in}}$, and of water outputs from the glacier, $Q_{\text {out }}$. Total water storage, $S$, is apportioned between subglacial and englacial reservoirs. Englacial water stored within the connected macroporosity of the glacier, $\phi$, governs the height of the effective water table, $z_{\mathrm{w}}$, which in turn controls water pressure, $P_{\mathrm{w}}$ and hence the effective pressure, $N$, at the glacier bed. High water pressure promotes sliding, $u_{\mathrm{b}}$ (inset). Cavities also grow by melt of their roofs. Cavities shrink by viscous deformation of their ice roofs, the rate of collapse controlled by the effective pressure. A negative feedback exists in the system in that sliding enlarges cavity crosssectional area, which draws down water from the englacial reservoir. This then reduces the water table height, $z_{w}$, and the associated water pressure, which reduces the sliding speed, $u_{\mathrm{b}}$.

due to melting of cavity walls and the third term represents collapse due to creep.

\subsection{Model results}

To assess how well this model captures the expectations outlined above, we drive it with two different water budgets: a simple, synthetic case, constructed to mimic the character of the Kennicott Glacier water budget (Fig. 6a), and the positive-degree-day based 2006 Kennicott Glacier water budget (Bartholomaus and others, 2008; Fig. 7a). In the synthetic case, two pairs of superimposed sine waves, representing diurnal and synoptic-scale fluctuations, make up both $Q_{\text {in }}$ and $Q_{\text {out }}$. After several synoptic cycles, both the water inputs and outputs taper smoothly to zero to simulate the onset of winter (Fig. 6a).

Both the synthetic and the data-driven model outputs capture some of the common characteristics of glacier motion (Figs 6e and 7e), particularly periods of rapid and diurnally variable motion. As determined by our choice of sliding law, the most rapid motion occurs when the englacial water pressure is closest to ice flotation. Englacial water responds more directly than subglacial water to $\partial S / \partial t$ (Figs 6c and $7 \mathrm{c}$ ). Diurnal-scale fluctuations, amounting to $2-3 \%$ of the ice flotation level, are present throughout both records. When the englacial storage reaches a significant portion of the volume required for flotation, effective pressure is lowest, and additional, modest increases in the englacial water 


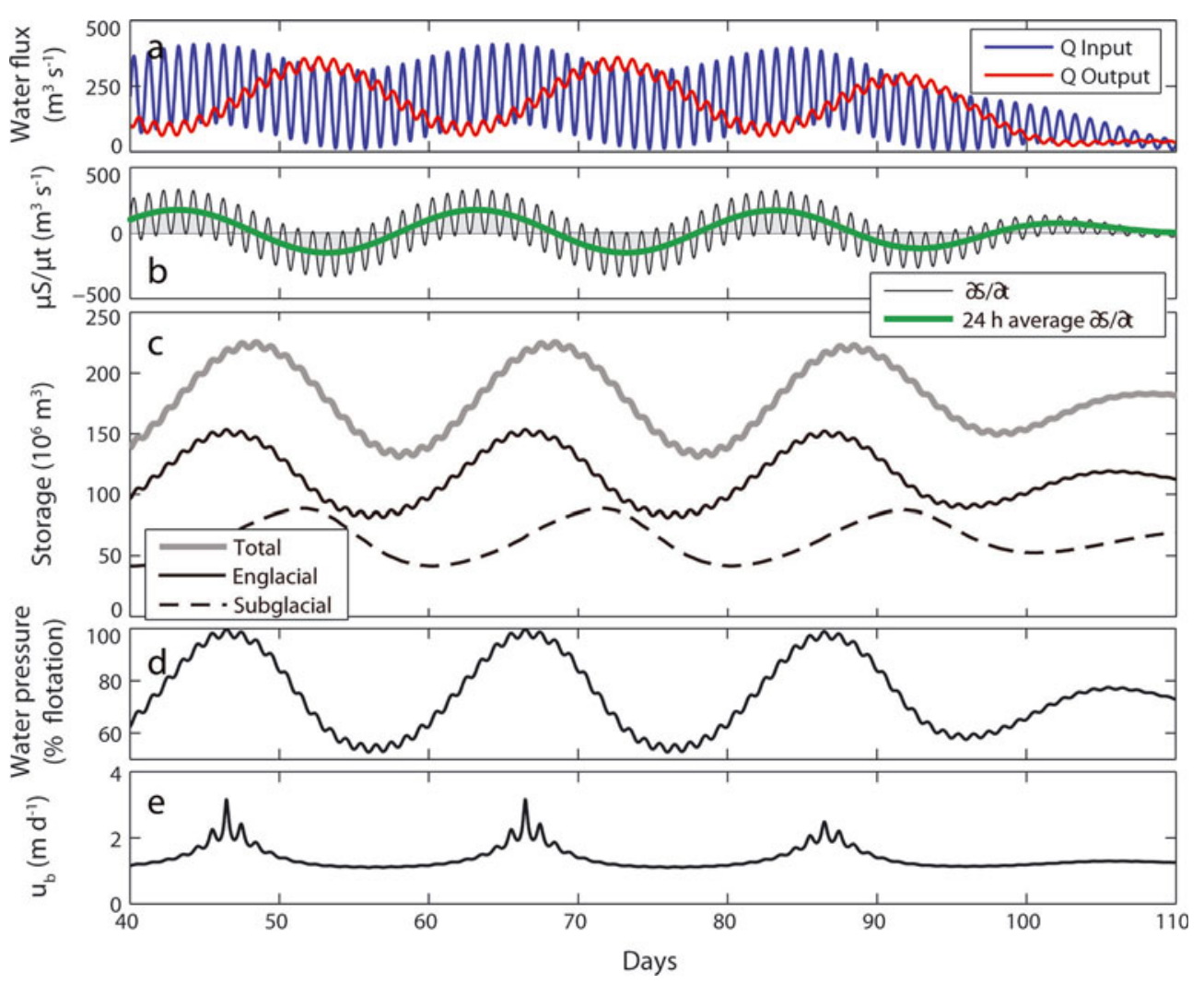

Fig. 6. Input for and results of our water-storage and basal-motion model: synthetic case. (a) Input and output components of the prescribed water balance. (b) $\partial S / \partial t$, the difference between the inputs and outputs. (c) Volumes of water storage: subglacial storage, englacial storage and the total water storage (sum of subglacial and englacial). (d) Percent of local glacier flotation level reached by englacial water storage. (e) Glacier surface speed, predicted by Equation (3). The diurnal velocity ratios for days with peak $u_{\mathrm{b}}$ (i.e. 47 and 67 ) are 0.63.

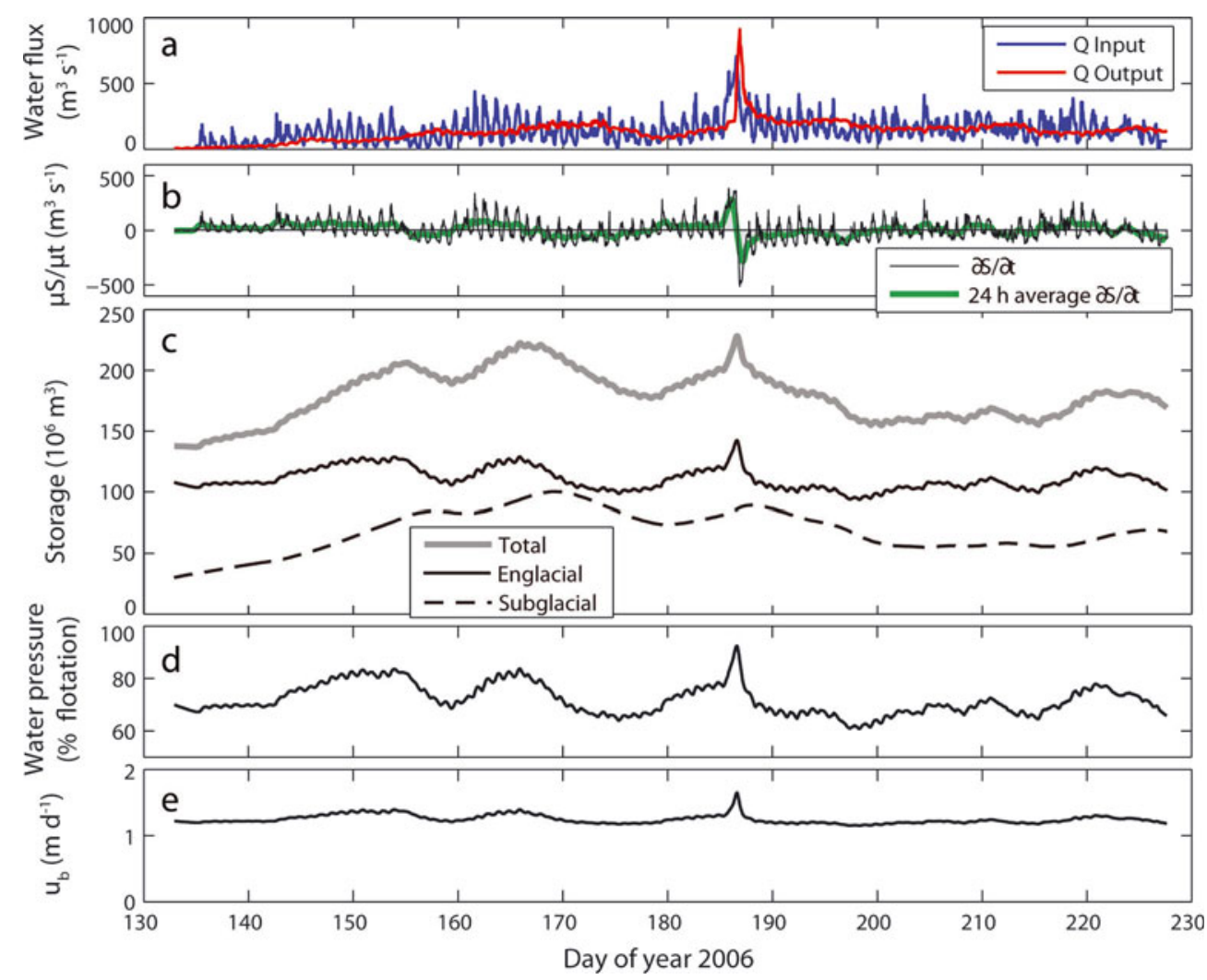

Fig. 7. Input for and results of our water-storage and basal-motion model: data-driven case. Panels are the same as Figure 6, but the model is driven by water inputs and outputs calculated at Kennicott Glacier (Bartholomaus and others, 2008). 


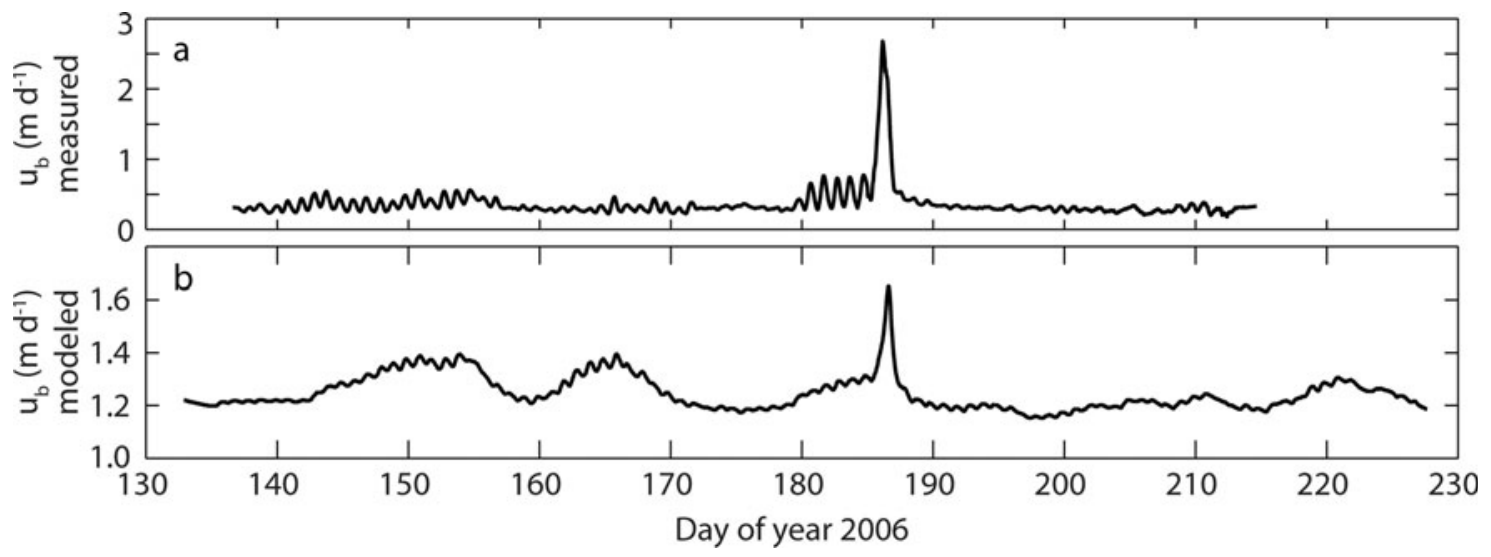

Fig. 8. Comparison between (a) observed speeds at GPS3 and (b) modeled speeds for Kennicott Glacier (same as Fig. 7e, but with different axis scaling).

storage lead to diurnal variations in basal motion. In both model runs, cavity melt (second term of Equation (4)), contributed insignificantly to cavity enlargement.

During the simulated winter, after day 100, the rate of change of storage, $\partial S / \partial t$, approaches zero and the volumes of englacial and subglacial storage stabilize; about $45 \%$ of the total storage is accounted for in the subglacial system, within cavities (Fig. 6c). Water pressure stabilizes at about $75 \%$ of ice flotation, intermediate between the highs and lows of the 'summer'. The high, stable winter water pressure predicted by the model is close to winter values observed at other glaciers (e.g. 84\% of flotation measured at Bench Glacier, Alaska (Harper and others, 2005)). Sliding speeds are maintained near their minimum rate, at $1.4 \mathrm{~m} \mathrm{~d}^{-1}$, far below the $3.2 \mathrm{~m} \mathrm{~d}^{-1}$ diurnal sliding maxima reached when $\partial S / \partial t$ was most positive.

The lag between maximum 24 hour averaged $\partial S / \partial t$ and maximum rates of basal motion varies between the synthetic and data-driven model runs in a subtle but important way. Despite having been run with identical parameter values, the amplitude of the synoptic englacial water-pressure fluctuations varies between the two runs. In the synthetic run, negative 24 hour averaged $\partial S / \partial t$ leads to a water-pressure drop from the flotation level to $45 \%$ of flotation, before rising again with positive averaged $\partial S / \partial t$ values (Fig. $6 \mathrm{~d}$ ). Due to the 10 days required for englacial water storage to recover from these synoptic falls in $\partial S / \partial t$, neither maximum diurnal velocity ratios nor peak rates of basal motion occur simultaneously with maximum averaged $\partial S / \partial t$, as has been described by Bartholomaus and others (2008) and as is modeled using the Kennicott water balance (Fig. 7). Instead, the diurnally varying basal motion lags the switch to positive $\partial S / \partial t$ by $7-8$ days and nearly coincides with the maximum total water storage. A somewhat similar lag is apparent in the Kennicott GPS data around day 160-165. At this time, the observed transition from Mode $B$ to Mode A motion lags the transition to positive 24 hour average $\partial S / \partial t$ by 3 days (Fig. 4 ). In the datadriven model (Fig. 7), the water pressure varies less (55$90 \%)$, so that water pressures quickly reach the level at which they are sensitive to additional water inputs, and the lag between the onset of positive average $\partial S / \partial t$ and diurnal velocity fluctuations is shorter, typically $1-3$ days. Therefore, the amplitude of synoptic and seasonal swings in englacial water pressure can strongly influence the strength of the link between the rate of change in water storage, $\partial S$ / $\partial t$, and basal motion. This influence is discussed further in Section 6.2.

\subsection{Comparison between model results and observed motion at Kennicott Glacier}

\subsubsection{Comparison of horizontal speeds}

The rates of basal motion predicted using our data-driven water storage model (Fig. 7) qualitatively follow the observed patterns of ice motion. For simplicity, we only compare the model with our longest record, that from GPS3 (Fig. 8); the other GPS receivers follow a similar pattern (Fig. 4). The periods with Mode A motion (i.e. aboveaverage speeds and large diurnal velocity ratios) in Figure 8 a coincide with periods with the same characteristics in Figure 8b. Partitioning the total water storage between englacial and subglacial reservoirs yields temporal patterns of motion with features that resemble the record of motion on Kennicott Glacier in three notable ways, although the absolute speeds vary. First, three periods of enhanced sliding with clear diurnal fluctuations occur prior to the drainage of HCL (days 140-156, 162-171 and 179185). Second, in the response to the HCL flood event itself, the timing is correct and the modeled structure of the speed spike resembles that observed. Third, the quiescent period after HCL drainage, which lacks significant speed-ups, is largely captured by the model. The model-predicted final pulse of motion between days 217 and 225 is present within the records of GPS4 and GPS5, though it is absent at the lower stations.

Several shortcomings in the model's predicted sliding are apparent. The modeled speeds are not as sensitive to fluctuations in glacier hydrology as they ought to be; the range of predicted speeds is not as great as is observed at both the diurnal and seasonal timescales. The minimum modeled speed is too great: $\sim 1.0 \mathrm{~m} \mathrm{~d}^{-1}$, rather than $0.2-$ $0.5 \mathrm{~m} \mathrm{~d}^{-1}$. We argue that a different set of parameters will yield a different set of predicted speeds, although the temporal pattern of motion will be the same. These deficiencies shine light on what is already clear: that a model as simple as the present one is insufficient to make absolute predictions of ice speed. However, for the discrimination between relative Modes of motion, and for capturing the essence of the response of the glacier to both daily and flood-related forcing, our model is successful. 


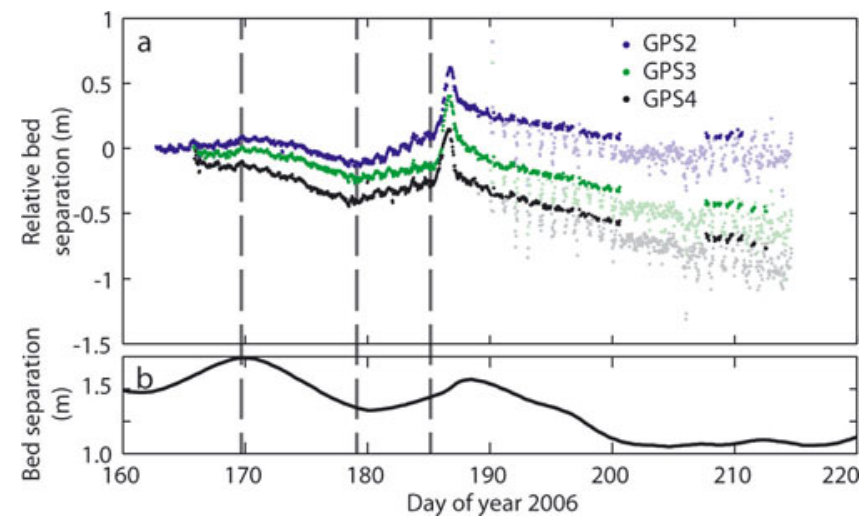

Fig. 9. Comparison between (a) measured, relative bed separation and (b) modeled bed separation. Bed separation is the average thickness of the water-filled space between the glacier and its bed. Horizontal and vertical axes have the same scale for both (a) and (b). In (a), faded points are significantly affected by loss of the GPS base station; we have no confidence in their accuracy. Vertical dashed lines are drawn through several major slope changes on both the (a) and (b) axes in order to facilitate comparison.

\subsubsection{Comparison between bed separation and subglacial storage}

Through the processes described in our conceptual model, the amount of water at the glacier bed (subglacial storage) and the average distance between the glacier bed and the glacier sole (bed separation) are tightly connected. When cavities are large, the glacier stores a considerable amount of water at the bed (Fountain and Walder, 1998), and bed separation should be high. On the other hand, when the amount of subglacial storage decreases by viscous deformation of ice roofs, the ice surface will fall as the average size of basal cavities declines. Therefore, another measure of the success of the water-storage and basal-motion model is comparison of the modeled time series of subglacial storage with a time series of bed separation derived from the GPS vertical displacement records. If modeled subglacial storage mimics the observed bed separation, then not only does our model predict broad patterns and amplitudes of variations of sliding, but it does so by faithfully partitioning stored water between englacial and subglacial reservoirs.

Changes to the observed vertical displacement (Fig. 2c) result from three phenomena: horizontal motion over an inclined bed, vertical strain, and changes in bed separation (Hooke and others, 1989; Anderson and others, 2004), such that

$$
\frac{\mathrm{d} s}{\mathrm{~d} t}=\frac{\mathrm{d} z}{\mathrm{~d} t}+\langle u\rangle \tan \beta-w_{\text {strain }}
$$

where $s$ is mean bed separation, $\langle u\rangle$ is the depth-averaged horizontal velocity, $\beta$ is the bed slope (positive when the bed dips in the direction of flow) and $w_{\text {strain }}$ is the vertical velocity resulting from horizontal strain rates. While we have no direct information about the slope of the Kennicott Glacier bed, observations of deglaciated alpine landscapes suggest that valley floors far from valley heads slope at roughly uniform angles of not more than a few percent. Bench Glacier, with simple geometry and near-uniform surface slope, has an average bed slope roughly parallel to its surface slopes (Anderson and others, 2004). Therefore, for the purposes of this calculation, we assume that $\beta \cong$ ice surface slope.
For Glen's flow law with an exponent $n=3$,

$$
\langle u\rangle=u_{\mathrm{s}}-\frac{1}{5} u_{\text {def }}
$$

where $u_{\mathrm{s}}$ is the measured ice surface speed and $u_{\text {def }}$ is the contribution of ice deformation to the ice surface speed $\left(u_{\text {def }}=u_{\mathrm{s}}-u_{\mathrm{b}}\right)$. At Black Rapids Glacier, an Alaskan glacier in a setting similar to Kennicott, roughly one-half of minimum, winter speeds were the result of basal motion (Heinrichs and others, 1996). We assume that minimum surface speeds (Table 1 ) at Kennicott are also subject to some steady basal motion; thus we calculate time series of $\langle u\rangle$ for each GPS station by subtracting one-tenth the minimum horizontal station speed from each velocity time series. The first two terms of Equation (5), $\frac{\mathrm{d} z}{\mathrm{~d} t}+\langle u\rangle \tan \beta$, are then quite similar to the slope-corrected vertical displacements already discussed and presented (Figs 2c and 3c), but reduced by a small fraction proportional to the minimum speed at each GPS station. Whether this 'small fraction' is one-tenth or one-fifth (the appropriate fraction for no steady basal motion) changes the downslope correction term of Equation (5) by no more than $10 \%$.

To calculate $w_{\text {strain, }}$ we must constrain both the horizontal strain rate in the glacier, and the glacier thickness. As only two measurements of ice thickness exist, both far from the Kennicott Glacier center line, we employ the equation for deformation velocity in a straight channel. Near $\mathrm{HCL}$, the ice is $350 \mathrm{~m}$ thick at a location only $400 \mathrm{~m}$ from the valley wall (Walder and others, 2006). At the Root Glacier center line, near DFL, the ice is $450 \mathrm{~m}$ thick (personal communication from E. Pettit, 2010). To place bounds on the ice thickness, we again consider cases in which $50 \%$ or $100 \%$ of the steady motion observed at each GPS receiver is the result of ice deformation (Table 1). The steady, uniform, surface velocity resulting from internal deformation, $u_{\text {def, }}$ is dependent on ice thickness through (Cuffey and Paterson, 2010)

$$
u_{\text {def }}=\frac{2 A}{N+1}\left(s_{f} \rho g \sin \alpha\right)^{n} H^{n+1},
$$

where $A$ is the flow-law parameter, $n$ is Glen's flow-law exponent (taken to be 3 ), $s_{\mathrm{f}}$ is a shape factor accounting for drag from the valley walls, $\rho$ is the density of ice $\left(917 \mathrm{~kg} \mathrm{~m}^{-3}\right)$, $\alpha$ is the ice surface slope and $H$ is the ice thickness. We select Cuffey and Paterson's (2010) recommended value of $A$ for temperate ice, $2.4 \times 10^{-24} \mathrm{~Pa}^{-3} \mathrm{~s}^{-1}$. Equation (7) is solved iteratively at each GPS station so that the parabolic shape factor is appropriate for the ice thickness. Two calculated ice thicknesses at each GPS station are reported in Table 1, corresponding to the two assumptions of steady basal motion.

We assume that across-flow gradients in velocity are insignificant compared to vertical and along-flow velocity gradients, and take ice to be incompressible, so

$$
w_{\text {strain }}=-\frac{\mathrm{d}\langle u\rangle}{\mathrm{d} x} H_{,}
$$

where $x$ is the along-flow coordinate. The longitudinal strain rates in Equation (8) are calculated as distance-weighted averages centered on each of the interior stations, GPS2GPS4.

With all the terms of Equation (5) solved at these three stations, we numerically integrate for $s$, the bed separation (Fig. 9a). These data-derived values of $s$ may be compared with the values of subglacial storage from our storage and sliding model (Fig. 7c) if we divide the volume of storage, 
$S_{\text {sub, }}$ by the basal area of our model glacier, $L W$. The longterm pattern and magnitudes of modeled bed separation follow the pattern and magnitudes of observed bed separation, increasing confidence that our model is properly partitioning stored water between subglacial and englacial reservoirs. The volume of water in subglacial storage, assuming a fixed horizontal area in which this water may be stored, and the magnitude of bed separation calculated from GPS observations, are essentially two measures of the same glacier-averaged subglacial cavity size.

\subsection{Model sensitivity}

Our model requires the selection of three parameters that govern the relationship between subglacial hydrology and basal motion. Each of these three parameters, $\gamma, C \tau_{b}{ }^{n}$ and $\phi$, is only weakly constrained by observations reported in the literature. Four reported values for $\gamma$, the exponent on the dependence of sliding speed on effective pressure, range from 0.18 to 0.4 (Jansson, 1995; Sugiyama and Gudmundsson, 2004). $C \tau_{\mathrm{b}}{ }^{n}$ has units that depend on the exponent $\gamma$, and varies from $1.5 \times 10^{-5} \mathrm{~m} \mathrm{~s}^{-1} \mathrm{~Pa}^{0.18}$ to $1.1 \times 10^{-3} \mathrm{~m} \mathrm{~s}^{-1} \mathrm{~Pa}^{0.4}$ (Jansson, 1995; Sugiyama and Gudmundsson, 2004). Estimates of englacial macroporosity (crevasses/fractures and moulins/conduits) that allow the free exchange of water with the bed (our $\phi$ ) are similarly limited. Estimates from Bradford and others (2009) place an upper bound on the water content (micro- and macroporosity) of Bench Glacier, $150 \mathrm{~km}$ southwest of Kennicott Glacier. Using ice-penetrating radar, they estimate a typical water content for the deeper portions of the glacier of 1.0$2.5 \%$. On Storglaciären, Sweden, analyses of borehole video reveal that englacial voids make up $1.3 \%$ of the observed glacier volume (Pohjola, 1994).

To test the sensitivity of our model, we ran the above synthetic experiment (Fig. 6) with values of $\gamma$ between 0.05 and $0.7, C \tau_{\mathrm{b}}{ }^{n}$ between $3 \times 10^{-6}$ and $3 \times 10^{-3}$, and $\phi$ between $0.1 \%$ and $3 \%$. As we are more interested in the timing and pattern of diurnal basal motion than the specific speeds, we present modeled diurnal velocity ratios as a metric of model success. In turn, we varied the values of these three parameters and ran our water-storage and basalmotion model with the synthetic water budget (Fig. 6a). For each set of the three parameters, the maximum diurnal velocity ratio of a post-spin-up synoptic cycle (e.g. days 4060 of Fig. 6e) is presented in Figure 10. In each slice of the three-dimensional parameter space (i.e. each panel of Fig. 10), two parameters are varied, and the third is held at the value used to produce Figures 6 and $7 \quad(\gamma=0.22$, $C \tau_{\mathrm{b}}{ }^{n}=3 \times 10^{-4}$ and $\phi=0.7 \%$ ). As discussed above, we consider that diurnal velocity ratios of $0.1-5$ indicate present and plausible diurnal velocity variations; this range is bracketed in bold black lines in Figure 10.

Parameter sets yielding diurnal velocity ratios of $0.1-5$ span the range of observed parameter values. When provided with the synthetic water balance of Figure 6, three of the four pairs of $C \tau_{b}{ }^{n}$ and $\gamma$ found in the literature will yield diurnal velocity ratios close to our bounds at an effective macroporosity of $0.7 \%$ (polygons in Fig. 10c). To bring the fourth pair of values, from Storglaciären, to a diurnal velocity ratio within our preferred range, $\phi$ would have to be $>0.7 \%$.

The depiction of parameter space in Figure 10 allows us to generalize the behavior of our model and discuss the general relationship between glacier hydrology and basal motion. The model is less sensitive to the selection of either $C \tau_{\mathrm{b}}{ }^{n}$ or $\gamma$ at low values of $\phi$ than at high values. For small $C \tau_{\mathrm{b}}{ }^{n}$ or $\gamma$, the model is less sensitive to the selection of the other parameter while $\phi=0.7 \%$. Effective macroporosity greater than $2 \%$, or $\gamma$ not between 0.1 and 0.6 , are combinations unlikely to allow a glacier to display diurnally fluctuating velocities, and would perhaps eliminate enhanced summer basal motion entirely. As enhanced summer basal motion is common to almost all glaciers, our sensitivity testing places some bounds on the expected range of these parameters, bounds that enclose the few values presented in previous studies (e.g. Jansson, 1995; Sugiyama and Gudmundsson, 2004; Fig. 10).

\section{INTERPRETATION AND DISCUSSION}

\subsection{Hydrology and basal motion of the glacier leading up to Hidden Creek Lake drainage}

The drainage of $\mathrm{HCL}$ was preceded by the most rapid ice flow recorded outside the 1.5 days directly impacted by the passage of floodwaters (Fig. 2b). Beginning on day 179, one of the transitions to Mode $A$ behavior, each day the glacier reach from GPS2 to GPS5 increased its speed en masse, with diurnal velocity ratios of approximately $2-3$. Simultaneously, bed separation increased (Fig. 2c). Throughout most of our field season, the furthest up-glacier GPS sites exhibited the highest speeds, although during the interval from day 179 to 185 GPS4 both maintained a higher average speed and attained higher daily maxima (Fig. 3b) than any other GPS site, including GPS5, $3.5 \mathrm{~km}$ up-glacier of GPS4. Thus, longitudinal strain rates were compressional between GPS3 and GPS4 but, unusually, extensional between GPS4 and GPS5. Following HCL drainage, GPS5 resumed speeds in excess of those at GPS4 for the duration of our measurements; that reach of glacier therefore went back into compression.

The rate of lake stage rise did not begin to decline until day 183 . Given that the hypsometry of $\mathrm{HCL}$ can be roughly approximated as a triangular trough, we see no evidence that the filling rate of HCL decreased, or that HCL began to drain, until several days after the start of GPS4's particularly rapid motion on day 179 . Thus, we do not associate the motion during days 179-183 (nor similarly during days 183185) with early leakage of water from HCL. Instead, we interpret the motion during days 179-185 as likely being the result of an increase in air temperature beginning on day 179. The increased input of meltwater likely encountered a subglacial hydrologic system that was substantially collapsed after the preceding low temperatures (Figs 2a and 9).

The ingredients that favor initiation of a jökulhlaup include the presence of a nearby conduit, a path for water to leak between the lake and the conduit, and a high potential gradient between lake and conduit. Prior to warm weather beginning on day 179, cavities beneath the reach of glacier from GPS2 to GPS5, which include the reach adjacent to $\mathrm{HCL}$, had substantially collapsed; bed separation was low (Fig. 9). Strong diurnal melt during days 179-185 then overwhelmed these cavities, leading to a period with strong diurnal velocity fluctuations and rapid basal motion (Fig. 7). We suggest that this sliding will increase the likelihood of a connection between lake and conduit (Knight and Tweed, 1991); this effect might have been augmented by crevassing observed between GPS4 and GPS5. Extensional strain rates visible between these stations in Figure $3 \mathrm{~b}$ 

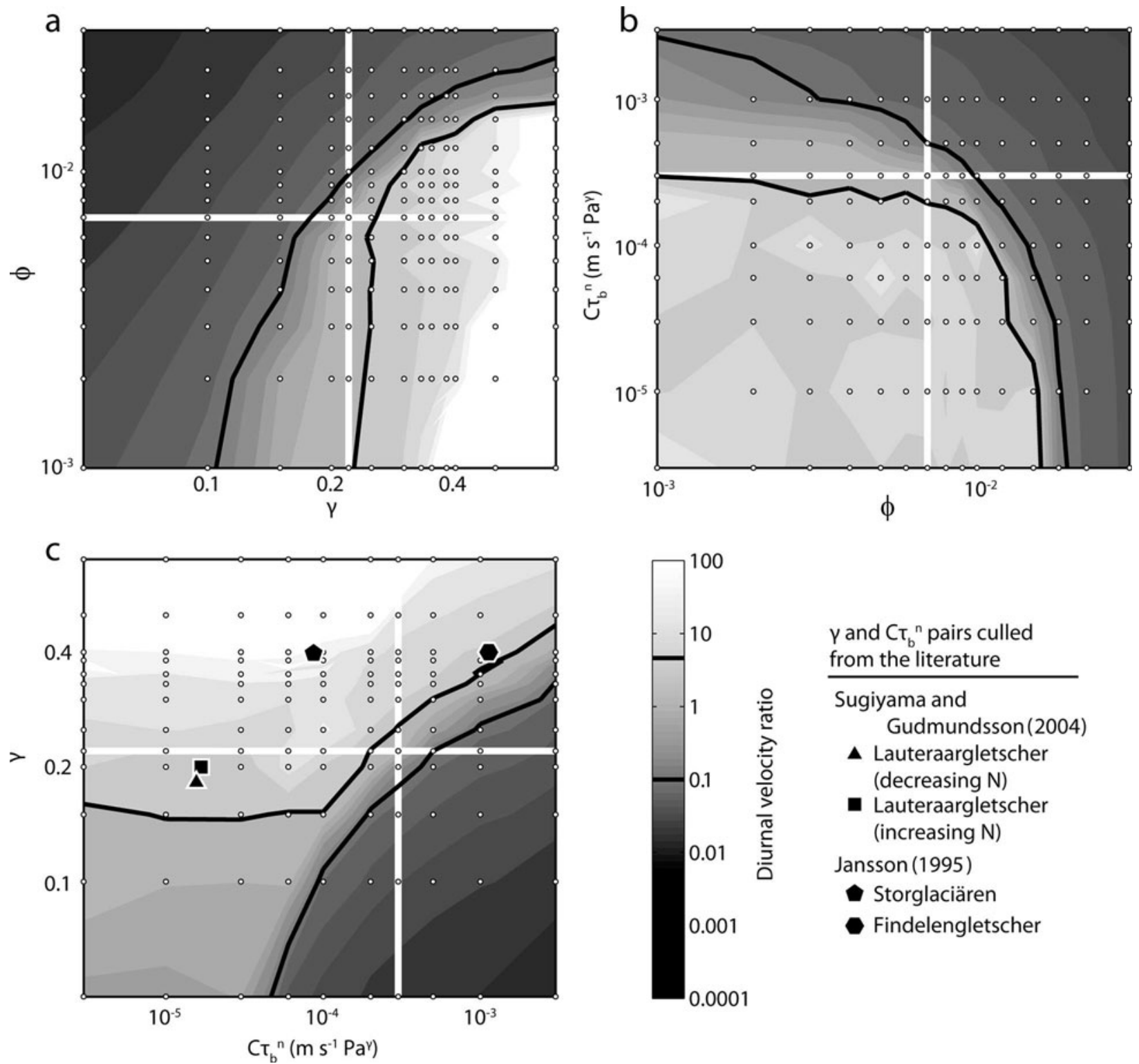

Fig. 10. Sensitivity of diurnal velocity ratios to three parameters: $\gamma, C \tau_{\mathrm{b}}{ }^{n}$ and $\phi$. The diurnal velocity ratio ((max. diurnal velocity-min. diurnal velocity)/min. diurnal velocity) associated with the maximum synthetic velocity for the synthetic water balance shown in Figure 6 a. Shading identifies the value of the diurnal velocity ratio; bold black lines bound the diurnal velocity ratios between 0.1 and 5 , realistic values for diurnal velocity ratios when present. Three panels are slices through the three-dimensional parameter space; straight, white lines show the location of two other slices. Diurnal velocity ratio (a) as a function of $\gamma$ and $\phi, C \tau_{\mathrm{b}}{ }^{n}=3 \times 10^{-4}$; (b) as a function of $\phi$ and $C \tau_{\mathrm{b}}{ }^{n}$, $\gamma=0.22$; and (c) as a function of $C \tau_{\mathbf{b}}{ }^{n}$ and $\gamma, \phi=7 \times 10^{-3}$. In (c), the values of $C \tau_{\mathbf{b}}{ }^{n}$ and $\gamma$ from other researchers are plotted with polygons. In each panel, the intersection of the thick, white lines represents the set of parameters used to create Figures 6 and 7 . Small white dots show measurements that are the source of the contouring. Crenulated, intricate nature of the pattern of diurnal velocity ratios greater than 30 reflects limits of model stability, not anticipated dependence of the ratio on model parameters.

are consistent with crevassing. This increase in connectivity is seen in other analogous systems; for example, sliding promotes increases in lateral connectivity and effective permeability in fault systems (Mallikamas and Rajaram, 2005). By this time in the melt season, it is likely that one or more conduits (Röthlisberger (R) channels) would have propagated to this elevation on the glacier, draining sideglacier lakes (e.g. Jumbo, then DFL) as it passes by. The few days of enhanced surface melt just prior to the jökulhlaup would have increased discharge of meltwater connecting to and then draining through this conduit system, which in turn would have lowered the pressure of the nearest channel as it grew to accept additional water (Röthlisberger, 1972). Decreasing the R-channel water pressure increases the head gradient between it and the lake. Eventually, the hydrologic connection is established and water flow begins, inevitably leading to a jökulhlaup (Nye, 1976).

\subsection{Drawdown feedback leads to regulation of the glacier sliding system}

Iken and Truffer (1997) described water-limited cavities as potential 'sticky spots' on the glacier bed. We may assess the 'stickiness' of isolated cavities by exploring the conceptual model outlined in Section 5.1. The growth of cavities through sliding increases the volume of subglacial storage and simultaneously draws down englacial water. The associated drop in water pressure will slow sliding, acting as a negative feedback or a regulator on the hydro-sliding 
system. Our intent in this section is to evaluate the relative importance of the various components involved in this feedback.

For a sliding law in the form of Equation (3), the rate of change of sliding speed with respect to water pressure is

$$
\frac{\mathrm{d} u_{\mathrm{b}}}{\mathrm{d} P_{\mathrm{w}}}=k \gamma\left(P_{\mathrm{i}}-P_{\mathrm{w}}\right)^{-(\gamma+1)}=k \gamma N^{-(\gamma+1)}
$$

where $P_{\mathrm{w}}$ is the water pressure $\left(=\rho_{\mathrm{w}} g z_{\mathrm{w}}\right)$ and $k=C \tau_{\mathrm{b}}{ }^{n}$.

We must evaluate the rate at which new cavity space is generated by sliding. Recall the picture of the glacier bed with evenly spaced cavities and a defined cavity-generating capacity of the bed, $f$. Ignoring for the moment the viscous collapse of cavities, the rate of generation of basal cavity volume per unit area of bed is simply

$$
\frac{\mathrm{d} s}{\mathrm{~d} t}=\frac{h w_{\mathrm{c}}}{\lambda_{x} \lambda_{y}} u_{\mathrm{b}}=f u_{\mathrm{b}}
$$

where $s$, bed separation, has units of length. The basal sliding serves to lengthen all cavities. Again, we have ignored the loss of water to the channelized portion of the subglacial system.

If this newly generated subglacial cavity volume is immediately filled with englacial water from connected porosity, the volume of englacial water must decrease as cavities grow, but increase as new meltwater is added to the glacial system. The rate of change of englacial water volume per unit area of bed is therefore

$$
\phi \frac{\mathrm{d} z_{\mathrm{w}}}{\mathrm{d} t}=\dot{m}-\frac{\mathrm{d} s}{\mathrm{~d} t}
$$

where $\dot{m}$ is the rate of water input to the glacier system (here assumed to be dominated by melt, with units of length over time). We may now assess how water pressure is reduced by sliding:

$$
\begin{aligned}
& \frac{\mathrm{d} P_{\mathrm{w}}}{\mathrm{d} t}=\rho_{\mathrm{w}} g \frac{\mathrm{d} z_{\mathrm{w}}}{\mathrm{d} t}=\frac{\rho_{\mathrm{w}} g}{\phi}\left(\dot{m}-\frac{\mathrm{d} s}{\mathrm{~d} t}\right) \\
& =\frac{\rho_{\mathrm{w}} g}{\phi}\left(\dot{m}-\frac{h w_{\mathrm{c}} u_{\mathrm{b}}}{\lambda_{x} \lambda_{y}}\right)=\frac{\rho_{\mathrm{w}} g}{\phi}\left(\dot{m}-f u_{\mathrm{b}}\right) .
\end{aligned}
$$

Inspection of this equation reveals that the greater the rate of melt input, the greater the rate of pressurization of the system (first term in parentheses). But the higher the sliding speed, the greater the rate at which water pressure is drawn down (second term in parentheses). Low porosity serves to amplify both effects: the smaller the porosity, the more sensitive the system. The cavity-generating capacity of the bed, $f$, also serves to amplify the drawdown effect.

The rate of change of sliding speed may now be cast as $\frac{\mathrm{d} u_{\mathrm{b}}}{\mathrm{d} t}=\frac{\mathrm{d} u_{\mathrm{b}}}{\mathrm{d} P_{\mathrm{w}}} \frac{\mathrm{d} P_{\mathrm{w}}}{\mathrm{d} t}$. If we ignore melt inputs $(\dot{m}=0)$, and consider a closed system with only feedbacks between cavity opening and englacial water drawdown (as might be the case in winter), this becomes simply

$$
\frac{\mathrm{d} u_{\mathrm{b}}}{\mathrm{d} t}=-\left(\frac{\gamma k \rho_{\mathrm{w}} g h w_{\mathrm{c}}}{\phi \lambda_{x} \lambda_{y} N^{\gamma+1}}\right) u_{\mathrm{b}}
$$

The solution of this ordinary differential equation for the history of sliding is a simple exponential decay function with timescale

$$
\tau=\frac{\phi \lambda_{x} \lambda_{y} N^{\gamma+1}}{\rho_{\mathrm{w}} g \gamma k h w_{\mathrm{c}}}=\left(\frac{1}{\rho_{\mathrm{w}} g}\right)\left(\frac{\phi}{f}\right)\left(\frac{N^{\gamma+1}}{\gamma k}\right) .
$$

The shorter this timescale, the stronger the drawdown feedback and the more sensitive the sliding/hydrology system. Inspection of this equation illuminates the roles of the various components of the system. In the final expression, we isolate physical constants in the first parentheses, the variables that govern the strengths of the englacial and subglacial feedbacks in the second parentheses, and the state of the hydrologic system and sensitivity of sliding to this state in the third parentheses. In general, the more cavity volume that is generated per unit of sliding, the stronger the feedback; the greater the cavity-forming capacity of the bed, $f$ (the taller and wider the cavities, and the smaller the spacing between cavities), the greater the cavity volume change per unit of sliding, and hence the greater the drawdown of the water table per unit of cavity volume. The smaller the porosity, the greater the drawdown, the amplifier of which we have already written.

The remaining dependence is on the effective pressure itself. The smaller the effective pressure, $N$ (i.e. the greater the water pressure), the shorter the timescale and hence the greater the feedback. The more nonlinear the dependence of sliding speed on effective pressure, as represented by $\gamma$, the stronger the effect. This formulation yields additional insight into the switches between Modes A and B, in particular the presence or absence of diurnal velocity variations. In our model, $N$ decreases towards zero ( $P_{\mathrm{w}}$ approaches flotation; Fig. 6d) while 24 hour averaged $\partial S / \partial t$ is positive (Fig. 6b). Eventually, $N$ may be sufficiently small such that $\tau$ falls below 1 day. At that point we can expect diurnal variations in sliding speed. In other words, the transition from Mode B to Mode A motion while water storage within the glacier is increasing (Bartholomaus and others, 2008) is a natural result of an effective pressure-dependent 'sliding law' (Equation (3)).

What are plausible values for these numbers, and how quickly might sliding rates change? If we find that the timescale is of order 1 year, the feedback will not be strong, and the regulation will instead fall on other governors of the system that we have ignored in this analysis: variations in melt rate, cavity collapse, and rates of passage of water to and from the conduit system. If, on the other hand, the timescales are much shorter than this, the drawdown feedback becomes important in understanding seasonal to daily sliding histories.

Consider the following values, used to generate Figures 6 and 7: $\phi=0.007$ (0.7\% porosity), $g=9.8 \mathrm{~m} \mathrm{~s}^{-2}$, $\rho_{\mathrm{w}}=1000 \mathrm{~kg} \mathrm{~m}^{-3}, h=1 \mathrm{~m}, w_{\mathrm{c}}=5 \mathrm{~m}, \lambda_{x}=\lambda_{y}=10 \mathrm{~m}$ (hence $f=0.05), \gamma=0.22$, and $k=C \tau_{\mathrm{b}}{ }^{n}=3 \times 10^{-4}$. Say, for example, the water pressure is $95 \%$ flotation, or $P_{\mathrm{w}}=0.95 P_{\mathrm{i}}$, hence $N=0.05 P_{\mathrm{i}}$. If the glacier thickness is $900 \mathrm{~m}$, the timescale $\tau$ is then 17 days. If the glacier is thinner, $500 \mathrm{~m}, \tau=8$ days. If the glacier is $900 \mathrm{~m}$, but $P_{\mathrm{w}}=0.99 P_{\mathrm{i}}, \tau=2.4$ days. If the glacier porosity is halved, $\tau=1.2$ days. As the timescale $\tau$ is inversely dependent on $f$, an order-of-magnitude increase in $f$ from one glacier bed to another will result in order-ofmagnitude decrease in the expected response time. While we have not included in this discussion the addition of new melt from the glacier surface or the viscous collapse of cavities, we point out that their inclusion in a more comprehensive analysis would further shorten the response timescale, $\tau$. It is clear from this scaling that the drawdown feedback may indeed be important on synoptic to daily timescales. The hydrologic state of the glacier and the nature of both bed and glacier should therefore matter.

With plausible values of the controlling parameters, this drawdown effect may yield very 'sticky' cavities, in which 
cavity growth can retard glacial motion, and therefore come into play as a regulator of the sliding system on temperate glaciers. Therefore, it ought not to be ignored in any hydrosliding analysis. Depending on the geometry of the subglacial system, on the thickness of the glacier and on the state of the hydrologic system at the time (governing the connectedness of conduit-fast flow routes and cavity-slow flow routes), this drawdown feedback may become the dominant player.

The clearest example of the importance of this drawdown feedback occurs during the winter, when surface melt is shut off. In the absence of continued water addition to the glacier's hydrologic system, the ice roof of the subglacial hydrologic system will collapse (cf. the last term on the righthand side of Equation (4)). The winter subglacial hydrologic system becomes increasingly disarticulated, resulting in a 'stickier' glacier bed, despite the fact that basal water pressure in these cavities will rise to equal the ice overburden pressure. Any small amount of sliding associated with this high $P_{\mathrm{w}}$ will increase the cavity volume and result in drawdown of englacial water pressure. The negative feedback during winter is therefore identical to that described in the episodic shearing of granular materials, in which dilation upon shearing pulls down the water pressure that caused the shearing event in the first place (Moore and Iverson, 2002).

\subsection{Weak connections between glacier hydrology and tidewater/outlet glacier dynamics}

Although diurnal velocity fluctuations and seasonal speedups are nearly ubiquitous below the equilibrium line of terrestrially terminating glaciers and ice sheets far from marine margins (Willis, 1995; Bartholomew and others, 2010), clear connections between glacier hydrology and glacier speed are rarely observed near the termini of lakeand marine-terminating glaciers (e.g. Echelmeyer and Harrison, 1990; Howat and others, 2008; Joughin and others, 2008). Our model suggests one potential explanation for this observation. As ice approaches the termini of lakeand marine-terminating glaciers, it most often experiences longitudinal strain rates that far exceed those observed on terrestrial glaciers. This is manifest in the last kilometers to tens of kilometers of glacier being chopped up by crevasses. We expect that this extensive crevassing ought to increase the macroporosity of the glacier above the threshold for which diurnal velocity fluctuations or seasonal meltenhanced ice flow may occur. As stated above, that threshold may be as low as $2 \%$, not far above the macroporosity measured at terrestrially terminating glaciers with less extreme strain rates (e.g. Pohjola, 1994; Bradford and others, 2009). Thus, while the mean water levels within gently sloping tidewater termini are at least as high as sea level (Pfeffer, 2007), the porosity of these glaciers may be so high that daily variations in water inputs are insufficient to change the subglacial water pressure substantially. If water pressures are insensitive to these water input fluctuations, then the rates of basal motion that they govern (Equation (3)) should also not vary on daily timescales.

\subsection{Importance of incorporating hydrologic transience in 'sliding laws'}

The results of our study indicate that efforts to predict changes in basal motion from temperature parameterizations alone, or from predicted changes in meltwater modeled using such methods (e.g. Parizek and Alley, 2004), will be unreliable unless they account for the evolution of the glacial hydrologic system (e.g. as in the present study, or Schoof, 2010). The hydrologic system is transient both because the meltwater additions vary in time and space and because the hydrologic system varies in its efficiency in transmitting the meltwater. The strong annual sliding cycle that results from the combining seasonal variation in meltwater inputs and evolving glacial-hydrologic system, described here for an alpine glacier system, has now been documented on outlet glaciers from the Greenland ice sheet (Bartholomew and others 2010; Sole and others, 2011). The key point is that meltwater inputs alone do not control basal motion. Positive correlations between glacier acceleration and meltwater inputs (such as inferred from partial degree-day models) will occur in some cases, but in general such correlations oversimplify the system because they fail to incorporate the important role of dynamics of the subglacial hydrologic system.

\section{CONCLUSIONS}

Observations of surface motion, meteorology and hydrology at Kennicott Glacier have illuminated how evolving glacier hydrology governs glacier motion. The sensitivity of glacier sliding to increases in water delivery to Kennicott Glacier varies greatly over the course of our nearly 100 days of observations. Sometimes, increased water delivery can lead to several-fold increases in sliding speed, whereas at other times the same increase in water delivery has almost no effect. Whether additional water is stored englacially or subglacially is critical in this relationship. In our model, englacial water storage acts as a buffer to the subglacial system, storing any water that the subglacial reservoir is unable to accept. Only persistent increases in total water storage (i.e. positive 24 hour averaged $\partial S / \partial t$ ) will cause water to rise englacially to levels at which rapid basal motion can occur. These episodes of rapid basal motion are most frequently manifest as diurnal velocity fluctuations, although the most rapid basal motion coincides with the most rapid increases in water storage, regardless of when that takes place. On Kennicott Glacier, this occurs during the drainage of HCL.

Our simple numerical model, based on the concepts of englacial/subglacial water partitioning, can reproduce many of the salient aspects of the observed sliding history when driven with the water inputs and outputs of Kennicott Glacier. Although a more sophisticated model is necessary to predict the absolute magnitudes of ice motion, and a spatially distributed model would be required to explore the phasing of the sliding along the glacier, the simplicity of our model allows easy exploration of the glacial and meteorological variables that govern glacial sliding. By employing an appropriate synthetic water balance, we have identified the ranges of parameters that predict realistic variations of diurnal sliding (Fig. 10).

We have shown that the drawdown effect on basal motion can be significant and can serve as a regulator of sliding at least under some conditions. Its efficacy is controlled by basal water pressure and the non-dimensional ratio of $f / \phi$, which will vary both between glaciers and from place to place on a glacier.

Finally, we emphasize that importance of transience in the glacier hydro-sliding system means that prerequisites to 
construction of a full model of sliding include both knowledge of the water input history to a glacier, and a model of the evolution of the subglacial hydrologic system on seasonal to daily timescales. This is the target of recent work on Greenland outlet glaciers (e.g. Bartholomew and others 2010; Sole and others, 2011), which appear to behave in a manner that is very similar to alpine glaciers. It also serves as the motivation for further work in the natural laboratory represented by Kennicott Glacier.

\section{ACKNOWLEDGEMENTS}

We gratefully acknowledge support for this research from the US National Science Foundation (NSF/EAR-0549566). Manuscript preparation was completed in part under NSF/ EAR-0810313. C. Larsen processed the GPS data with GIPSY. T. Bartholomaus thanks C. Larsen and R. Hock for support and encouragement through the conclusion of this work. We sincerely acknowledge the careful reviews of I. Howat and two anonymous reviewers, whose comments improved the clarity and focus of the paper. The University Navstar Consortium (UNAVCO) and Veco/CH2M HILL Polar Services provided indispensable GPS and logistical support. The Wrangell Mountains Center, McCarthy, Alaska, and E. LaChapelle provided lodging at our field site.

\section{REFERENCES}

Anderson, R.S. and 6 others. 2004. Strong feedbacks between hydrology and sliding of a small alpine glacier. J. Geophys. Res., 109(F3), F03005. (10.1029/2004JF000120.)

Anderson, R.S., J.S. Walder, S.P. Anderson, D.C. Trabant and A.G. Fountain. 2005. The dynamic response of Kennicott Glacier, Alaska, USA, to the Hidden Creek Lake outburst flood. Ann. Glaciol., 40, 237-242.

Anderson, S.P., K.M.H. Fernald, R.S. Anderson and N.F. Humphrey. 1999. Physical and chemical characterization of a spring flood event, Bench Glacier, Alaska, U.S.A.: evidence for water storage. J. Glaciol., 45(150), 177-189.

Anderson, S.P. and 6 others. 2003a. Integrated hydrologic and hydrochemical observations of Hidden Creek Lake jökulhlaups, Kennicott Glacier, Alaska. J. Geophys. Res., 108(F1), 6003. (10.1029/2002JF000004.)

Anderson, S.P., S.A. Longacre and E.R. Kraal. 2003b. Patterns of water chemistry and discharge in the glacier-fed Kennicott River, Alaska: evidence for subglacial water storage cycles. Chemical Geol., 202(3-4), 297-312.

Bartholomaus, T.C., R.S. Anderson and S.P. Anderson. 2008. Response of glacier basal motion to transient water storage. Nature Geosci., 1(1), 33-37.

Bartholomew, I., P. Nienow, D. Mair, A. Hubbard, M.A. King and A. Sole. 2010. Seasonal evolution of subglacial drainage and acceleration in a Greenland outlet glacier. Nature Geosci., 3(6), 408-411.

Bindschadler, R. 1983. The importance of pressurized subglacial water in separation and sliding at the glacier bed. J. Glaciol., 29(101), 3-19.

Bradford, J.H., J. Nichols, T.D. Mikesell and J.T. Harper. 2009. Continuous profiles of electromagnetic wave velocity and water content in glaciers: an example from Bench Glacier, Alaska, USA. Ann. Glaciol., 50(51), 1-9.

Clarke, G.K.C. 2003. Hydraulics of subglacial outburst floods: new insights from the Spring-Hutter formulation. J. Glaciol., 49(165), 299-313.

Colgan, W. and 7 others. 2011. The annual glaciohydrology cycle in the ablation zone of the Greenland ice sheet: Part 1. Hydrology model. J. Glaciol., 57(204), 697-709.
Cuffey, K.M. and W.S.B. Paterson. 2010. The physics of glaciers. Fourth edition. Oxford, Butterworth-Heinemann.

Echelmeyer, K. and W.D. Harrison. 1990. Jakobshavns Isbræ, West Greenland: seasonal variations in velocity - or lack thereof. J. Glaciol., 36(122), 82-88.

Fountain, A.G. and J.S. Walder. 1998. Water flow through temperate glaciers. Rev. Geophys., 36(3), 299-328.

Fudge, T.J., J.T. Harper, N.F. Humphrey and W.T. Pfeffer. 2005. Diurnal water-pressure fluctuations: timing and pattern of termination below Bench Glacier, Alaska, USA. Ann. Glaciol., 40, 102-106.

Gregorius, T. 1996. GIPSY OASIS II: how it works. Newcastle upon Tyne, University of Newcastle upon Tyne. Department of Geomatics.

Harper, J.T., N.F. Humphrey, W.T. Pfeffer, T. Fudge and S. O'Neel. 2005. Evolution of subglacial water pressure along a glacier's length. Ann. Glaciol., 40, 31-36.

Harper, J.T., N.F. Humphrey, W.T. Pfeffer and B. Lazar. 2007. Two modes of accelerated glacier sliding related to water. Geophys. Res. Lett., 34(12), L12503. (10.1029/2007GL030233.)

Harper, J.T., J.H. Bradford, N.F. Humphrey and T.W. Meierbachtol. 2010. Vertical extension of the subglacial drainage system into basal crevasses. Nature, 467(7315), 579-582.

Heinrichs, T.A., L.R. Mayo, K.A. Echelmeyer and W.D. Harrison. 1996. Quiescent-phase evolution of a surge-type glacier: Black Rapids Glacier, Alaska, U.S.A. J. Glaciol., 42(140), 110-122.

Hock, R., A. Iken and A. Wangler. 1999. Tracer experiments and borehole observations in the overdeepening of Aletschgletscher, Switzerland. Ann. Glaciol., 28, 253-260.

Hooke, R.LeB., P. Calla, P. Holmlund, M. Nilsson and A. Stroeven. 1989. A 3 year record of seasonal variations in surface velocity, Storglaciären, Sweden. J. Glaciol., 35(120), 235-247.

Howat, I.M., S. Tulaczyk, E. Waddington and H. Björnsson. 2008. Dynamic controls on glacier basal motion inferred from surface ice motion. J. Geophys. Res., 113(F3), F03015. (10.1029/ 2007JF000925.)

Hubbard, B.P., M.J. Sharp, I.C. Willis, M.K. Nielsen and C.C. Smart. 1995. Borehole water-level variations and the structure of the subglacial hydrological system of Haut Glacier d'Arolla, Valais, Switzerland. J. Glaciol., 41(139), 572-583.

Iken, A. and R.A. Bindschadler. 1986. Combined measurements of subglacial water pressure and surface velocity of Findelengletscher, Switzerland: conclusions about drainage system and sliding mechanism. J. Glaciol., 32(110), 101-119.

Iken, A. and M. Truffer. 1997. The relationship between subglacial water pressure and velocity of Findelengletscher, Switzerland, during its advance and retreat. J. Glaciol., 43(144), 328-338.

Iken, A., H. Röthlisberger, A. Flotron and W. Haeberli. 1983. The uplift of Unteraargletscher at the beginning of the melt season a consequence of water storage at the bed? J. Glaciol., 29(101), 28-47.

Jansson, P. 1995. Water pressure and basal sliding on Storglaciären, northern Sweden. J. Glaciol., 41(138), 232-240.

Joughin, I., S.B. Das, M.A. King, B.E. Smith, I.M. Howat and T. Moon. 2008. Seasonal speedup along the western flank of the Greenland Ice Sheet. Science, 320(5877), 781-783.

Julien, P.Y. 1995. Erosion and sedimentation. Cambridge, Cambridge University Press.

Kamb, B. 1987. Glacier surge mechanism based on linked cavity configuration of the basal water conduit system. J. Geophys. Res., 92(B9), 9083-9100.

Kessler, M.A. and R.S. Anderson. 2004. Testing a numerical glacial hydrological model using spring speed-up events and outburst floods. Geophys. Res. Lett., 31(18), L18503. (10.1029/ 2004GL020622.)

Knight, P.G. and F.S. Tweed. 1991. Periodic drainage of icedammed lakes as a result of variations in glacier velocity. Hydrol. Process., 5(2), 175-184. 
Mair, D., P. Nienow, I. Willis and M. Sharp. 2001. Spatial patterns of glacier motion during a high-velocity event: Haut Glacier d'Arolla, Switzerland. J. Glaciol., 47(156), 9-20.

Mair, D., P. Nienow, M. Sharp, T. Wohlleben and I. Willis. 2002. Influence of subglacial drainage system evolution on glacier surface motion: Haut Glacier d'Arolla, Switzerland. J. Geophys. Res., 107(B8), 2175. (10.1029/2001JB000514.)

Mallikamas, W. and H. Rajaram. 2005. On the anisotropy of the aperture correlation and effective transmissivity in fractures generated by sliding between identical self-affine surfaces. Geophys. Res. Lett., 32(11), L11401. (10.1029/2005GL022859.)

Moore, P.L. and N.R. Iverson. 2002. Slow episodic shear of granular materials regulated by dilatant strengthening. Geology, 30(9), 843-846.

Nienow, P., M. Sharp and I. Willis. 1998. Seasonal changes in the morphology of the subglacial drainage system, Haut Glacier d'Arolla, Switzerland. Earth Surf. Process. Landf., 23(9), 825-843.

Nye, J.F. 1976. Water flow in glaciers: jökulhlaups, tunnels and veins. J. Glaciol., 17(76), 181-207.

Parizek, B.R. and R.B. Alley. 2004. Implications of increased Greenland surface melt under global-warming scenarios: icesheet simulations. Quat. Sci. Rev., 23(9-10), 1013-1027.

Pfeffer, W.T. 2007. A simple mechanism for irreversible tidewater glacier retreat. J. Geophys. Res., 112(F3), F03S25. (10.1029/ 2006JF000590.)

Pimentel, S., G.E. Flowers and C.G. Schoof. 2010. A hydrologically coupled higher-order flow-band model of ice dynamics with a Coulomb friction sliding law. J. Geophys. Res., 115(F4), F04023. (10.1029/2009JF001621.)

Pohjola, V.A. 1994. TV-video observations of englacial voids in Storglaciären, Sweden. J. Glaciol., 40(135), 231-240.

Raymond, C.F., R.J. Benedict, W.D. Harrison, K.A. Echelmeyer and M. Sturm. 1995. Hydrological discharges and motion of Fels and Black Rapids Glaciers, Alaska, U.S.A.: implications for the structure of their drainage systems. J. Glaciol., 41(138), 290-304.
Rickman, R.L. and D.S. Rosenkrans. 1997. Hydrologic conditions and hazards in the Kennicott River Basin, Wrangell-St. Elias National Park and Preserve, Alaska. USGS Water-Resour. Invest. Rep. 96-4296.

Röthlisberger, H. 1972. Water pressure in intra- and subglacial channels. J. Glaciol., 11(62), 177-203.

Schoof, C. 2005. The effect of cavitation on glacier sliding. Proc. $R$. Soc. London, Ser. A, 461(2055), 609-627.

Schoof, C. 2010. Ice-sheet acceleration driven by melt supply variability. Nature, 468(7325), 803-806.

Shepherd, A., A. Hubbard, P. Nienow, M. McMillan and I. Joughin. 2009. Greenland ice sheet motion coupled with daily melting in late summer. Geophys. Res. Lett., 36(1), L01501. (10.1029/ 2008GL035758.)

Sole, A.J. and 6 others. 2011. Seasonal speedup of a Greenland marine-terminating outlet glacier forced by surface meltinduced changes in subglacial hydrology. J. Geophys. Res., 116(F3), F03014. (10.1029/2010JF001948.)

Sugiyama, S. and G.H. Gudmundsson. 2004. Short-term variations in glacier flow controlled by subglacial water pressure at Lauteraargletscher, Bernese Alps, Switzerland. J. Glaciol., 50(170), 353-362.

Sugiyama, S., A. Bauder, P. Weiss and M. Funk. 2007. Reversal of ice motion during the outburst of a glacier-dammed lake on Gornergletscher, Switzerland. J. Glaciol., 53(181), 172-180.

Truffer, M., R.J. Motyka, M. Hekkers, I.M. Howat and M.A. King. 2009. Terminus dynamics at an advancing glacier: Taku Glacier, Alaska. J. Glaciol., 55(194), 1052-1060.

Vieli, A., M. Funk and H. Blatter. 2001. Flow dynamics of tidewater glaciers: a numerical modelling approach. J. Glaciol., 47(159), 595-606.

Walder, J.S. and 6 others. 2006. Local response of a glacier to annual filling and drainage of an ice-marginal lake. J. Glaciol. 52(178), 440-450.

Willis, I.C. 1995. Intra-annual variations in glacier motion: a review. Progr. Phys. Geogr., 19(1), 61-106. 